\title{
Developmental stage determines estrogen receptor alpha expression and non-genomic mechanisms that control IGF-1 signaling and mammary proliferation in mice
}

Jie Tian, ${ }^{1}$ Thomas R. Berton, ${ }^{1}$ Stephanie H. Shirley, ${ }^{1,2}$ Isabel Lambertz ${ }^{1}$ Irma B. Gimenez-Conti, 1,2 John DiGiovanni, ${ }^{1,2}$ Kenneth S. Korach, ${ }^{3}$ Claudio J. Conti, ${ }^{1,2}$ and Robin Fuchs-Young,,2

${ }^{1}$ Department of Molecular Carcinogenesis, The University of Texas M.D. Anderson Cancer Center, Smithville, Texas, USA. ${ }^{2}$ The University of Texas Graduate School of Biomedical Sciences at Houston, The University of Texas M.D. Anderson Cancer Center, Houston, Texas, USA. ${ }^{3}$ Laboratory of Reproductive and Developmental Toxicology, National Institute of Environmental Health Sciences, Research Triangle Park, North Carolina, USA.

Insulin like growth factor-1 (IGF-1) stimulates increased proliferation and survival of mammary epithelial cells and also promotes mammary tumorigenesis. To study the effects of IGF-1 on the mammary gland in vivo, we used BK5.IGF-1 transgenic (Tg) mice. In these mice, IGF-1 overexpression is controlled by the bovine keratin 5 promoter and recapitulates the paracrine exposure of breast epithelium to stromal IGF-1 that is seen in women. Studies have shown that BK5.IGF-1 Tg mice are more susceptible to mammary tumorigenesis than wild-type littermates. Investigation of the mechanisms underlying increased mammary cancer risk, reported here, revealed that IGF-1 preferentially activated the PI3K/Akt pathway in glands from prepubertal Tg mice, resulting in increased cyclin D1 expression and hyperplasia. However, in glands from postpubertal Tg mice, a pathway switch occurred and activation of the Ras/Raf/MAPK pathway predominated, without increased cyclin D1 expression or proliferation. We further showed that in prepubertal Tg glands, signaling was mediated by formation of an ER $\alpha$ /IRS-1 complex, which activated IRS-1 and directed signaling via the PI3K/Akt pathway. Conversely, in postpubertal Tg glands, reduced ER $\alpha$ expression failed to stimulate formation of the $\mathrm{ER} \alpha / \mathrm{IRS}-1$ complex, allowing signaling to proceed via the alternate Ras/Raf/MAPK pathway. These in vivo data demonstrate that changes in ER $\alpha$ expression at different stages of development direct IGF-1 signaling and the resulting tissue responses. As ER $\alpha$ levels are elevated during the prepubertal and postmenopausal stages, these may represent windows of susceptibility during which increased IGF-1 exposure maximally enhances breast cancer risk.

\section{Introduction}

IGF-1 is an important mediator of cellular proliferation and survival, with critical effects on the growth, development, and homeostasis of responsive tissues. IGF-1 has also been implicated in a variety of different types of cancers, particularly breast cancer, due to its mitogenic and antiapoptotic effects on mammary epithelial cells $(1,2)$. In vitro studies show that IGF-1 binds to its cognate receptor (IGF-1R) and activates an extended signaling network that regulates essential physiological functions and also contributes to transformation and promotion of cancer cell growth $(3,4)$. Upon activation by ligand binding, the IGF-1R tyrosine kinase recruits and phosphorylates several intracellular substrates, such as IRS-1 and Src homology 2 domain-containing (Shc) (5). Both IRS- 1 and Shc bind to the adapter protein, growth factor receptorbound 2 (Grb2), and the associated guanine nucleotide exchange protein, son of sevenless (SOS), leading to stimulation of the Ras/ Raf/MAPK pathway $(6,7)$.

IRS-1 also serves as a multisite docking protein for PI3K, whose major downstream effector is the serine/threonine protein kinase Akt. The PI3K/Akt pathway has been shown to play a pivotal role in the genesis of cancer and contributes to cell cycle entry, cell growth,

Conflict of interest: The authors have declared that no conflict of interest exists. Citation for this article: J Clin Invest. 2012;122(1):192-204. doi:10.1172/JCI42204. and cell survival, through activation of multiple downstream effectors of proliferation and tumorigenesis (8-10). Recently, Creighton et al. used microarray analysis to identify transcriptional targets in MCF-7 breast cancer cells treated with IGF-1 (11). This group found that IGF-1 treatment stimulates increased expression of numerous cyclins and PI3K family members, but also noted differences between the profiles resulting from acute compared with chronic exposure. These studies identify an IGF-1 "activation signature" that correlates with poor prognosis and reduced survival in human breast cancer samples. However, others using clinical samples have reported an inverse association between the expression of IGF-1 and IGF binding protein 3 (IGFBP3) and human breast tumor aggressiveness $(12,13)$, indicating the need for additional studies to fully elucidate molecular mechanisms in vivo.

Collectively, reports have identified an extensive signal transduction network responsible for the biological actions of IGF-1. However, since most of the signaling work has been carried out with transformed or immortal cells in vitro, the impact of the physiological context and developmental stage has received inadequate attention, particularly in young individuals. Some fundamental questions remain unresolved, including the relative importance and/or unique functions of the two major signal transduction pathways, PI3K/Akt and Ras/Raf/MAPK, that are activated by the IGF-1/IGF-1R axis. Furthermore, the impact of 
tissue versus circulating levels of IGF-1 and role of the crosstalk between the IGF-1 downstream signaling network and other pathways, particularly those involving the estrogen receptor $\alpha(\mathrm{ER} \alpha)$, have not been elucidated in susceptible tissues in vivo.

To study the role of IGF-1 in mammary differentiation and breast cancer development in vivo, our laboratory characterized the BK5.IGF-1 Tg model, in which overexpression of human IGF-1 is under the control of the bovine keratin 5 (BK5) promoter. In the mammary gland, this promoter drives IGF-1 expression in myoepithelial cells, where it affects the adjacent ductal epithelium in a paracrine manner (14). Compared with previous Tg IGF-1 models using whey acidic protein (WAP) or mouse mammary tumor virus (MMTV) promoters $(15,16)$, BK5 drives constitutive transgene expression in mammary glands, where it is detectable at birth and persists throughout adulthood. An additional advantage is that the paracrine/juxtacrine effects of IGF-1 recapitulate, more than in other models, the exposure of breast epithelium to stromal IGF-1 observed in women. Thus, the BK5.IGF-1 Tg mouse provides a unique model for investigating the tissue responses to local overexpression of IGF-1 and allows assessment of the impact of the endogenous hormonal milieu on these responses.

Our previously published results show that BK5.IGF-1 mice are more susceptible to mammary tumorigenesis than WT littermates (14). Thirty-one percent of the $\mathrm{Tg}$ mice develop spontaneous estrogen receptor-positive $\left(\mathrm{ER}^{+}\right)$adenocarcinomas, with an overall mean tumor latency of 40.9 weeks, compared with $0 \%$ incidence in WT mice (14). BK5.IGF-1 mice are also more susceptible to 7,12-dimethylbenz $[a]$ anthracene-induced (DMBA-induced) carcinogenesis, with $74 \%$ developing mammary tumors, with an average latency of 19.9 weeks, while only $29 \%$ of the DMBA-treated WT mice develop mammary tumors, with an average latency of 43.3 weeks (14).

Mammary glands from prepubertal BK5.IGF-1 Tg mice are hyperplastic and have significantly increased proliferation in the ductal epithelium compared with age-matched WT mice, as measured by BrdU incorporation. Surprisingly, mammary glands from postpubertal Tg mice do not have increased BrdU incorporation compared with those from age-matched WT littermates, even though expression of Tg IGF-1 is not reduced in these older animals (14). This finding was unexpected, because the widely accepted mechanism of IGF-1-induced tumor promotion involves enhanced proliferation following carcinogen treatment, as previously shown in skin (17). The lack of a proliferative response to IGF- 1 in the mammary epithelium of glands from postpubertal animals suggests that unique, tissue-specific, developmental mechanisms contribute to IGF-1-mediated mammary tumorigenesis.

In order to better understand the molecular mechanisms mediating the biological effects of IGF-1 in the mammary gland during specific windows of susceptibility, we carried out the present study on susceptible tissues from pre- and postpubertal mice. Results presented here show that differences in the proliferative effects of IGF-1 in mammary gland reflected differential activation of distinct signal transduction pathways downstream of IGF-1R. Before puberty, IGF-1-induced signaling proceeded primarily through the PI3K/Akt pathway, but at puberty a "switch" to the Ras/Raf/ MAPK pathway occurred. Our studies also revealed that ER $\alpha$ expression levels, which varied depending on the hormonal milieu, played a pivotal role in mediating this signaling change and the subsequent proliferative effects in mammary tissue. Crossing the BK5.IGF-1 Tg mice with ER $\alpha$ knockout (ERKO) mice also demonstrated the absolute requirement for $\mathrm{ER} \alpha$ in mediating the prolif- erative effects of IGF-1 in mammary epithelium. These findings offer insight into the reported age-dependent association between obesity, IGF-1 levels, and breast cancer risk and suggest that developmental stages when estrogen $\left(E_{2}\right)$ is low and $E R \alpha$ expression is elevated are periods of increased susceptibility to the proliferative, pro-tumorigenic effects of IGF-1.

\section{Results}

IGF-1 activates distinct pathways in pre-and postpubertal mammary glands. To investigate the impact of paracrine exposure to Tg IGF-1 on mammary tumorigenesis in vivo, we evaluated the two main IGF-1 signal transduction pathways in susceptible glands from prepubertal (4-5 weeks old) and postpubertal (8-13 weeks old) WT and Tg mice.

Western blots, using specific anti-p-Akt (Ser473), revealed that Akt phosphorylation was significantly increased in prepubertal Tg mammary glands, compared with those from age-matched WT mice (Figure 1A). On the other hand, Erk1/2 activation, evaluated with an antibody against phosphorylated residues Thr202/ Tyr204, was not elevated in glands from Tg mice of this age. This activation of Akt was also associated with a modest, but significant, increase in the phosphorylation of its downstream effector mTOR at Ser2448 (Figure 1A).

Conversely, in postpubertal animals, Tg IGF-1 activated predominantly the Ras/Raf/MAPK pathway. As shown in Figure $1 \mathrm{~B}, \mathrm{p}$-Akt levels were similar in mammary glands from WT and $\mathrm{Tg}$ mice, while levels of $\mathrm{p}$-Erk $1 / 2$ were significantly elevated in $\mathrm{Tg}$ compared with age-matched WT mice. Interestingly, mTOR phosphorylation was also elevated in glands from postpubertal $\mathrm{Tg}$ mice, indicating that signal transduction via either pathway resulted in activation of $\mathrm{mTOR}$.

These results indicate that in prepubertal glands, Tg IGF-1 preferentially stimulated signaling via the Akt pathway, while signaling in postpubertal glands proceeded predominantly via the MAPK pathway. In previously published studies with this model, we presented evidence demonstrating that the biological differences in the response to paracrine IGF-1 stimulation in prepubertal and postpubertal BK5.IGF-1 $\mathrm{Tg}$ mice are not the result of reduction in the expression of the transgene IGF-1 over time (14).

The activation of Akt and/or MAPK signaling by Tg IGF-1 in mammary glands was also analyzed by immunohistochemistry. As shown in Figure 1C, Tg IGF-1 stimulated a strong increase in the intensity of p-Akt staining in the ductal epithelium of prepubertal but not postpubertal glands. Compared with age-matched WT mice, mammary epithelial cells in Tg postpubertal, but not prepubertal, mice had elevated p-Erk $1 / 2$ levels. These findings demonstrate that the signaling "switch" identified in the Western blots reflected changes in the mammary epithelium.

Cyclin D1 is a downstream target of IGF-1, ER $\alpha$, and other proliferative pathways and is one of the key regulators of entry into the cell cycle $(18,19)$. To assess the impact of Tg IGF-1 on cyclin D1 expression, we performed Western blot analysis of protein extracts from pre- and postpubertal mammary glands from WT and $\mathrm{Tg}$ mice. As shown in Figure 1, D and E, cyclin D1 protein expression was significantly higher in prepubertal Tg compared with WT glands. However, cyclin D1 levels were not elevated in glands from postpubertal $\mathrm{Tg}$ mice. These results are in agreement with our previously reported findings that epithelial proliferation, as measured by BrdU incorporation, is increased in $\mathrm{Tg}$ glands from prepubertal but not postpubertal mice (14). 
A
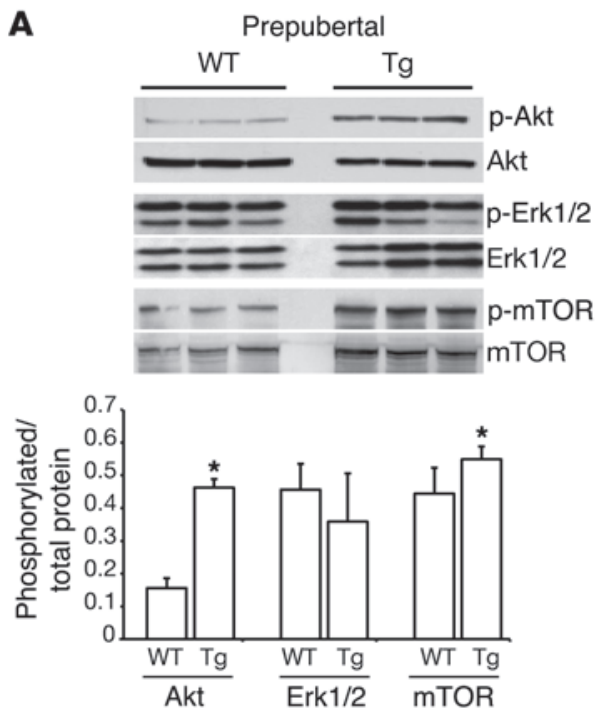

C
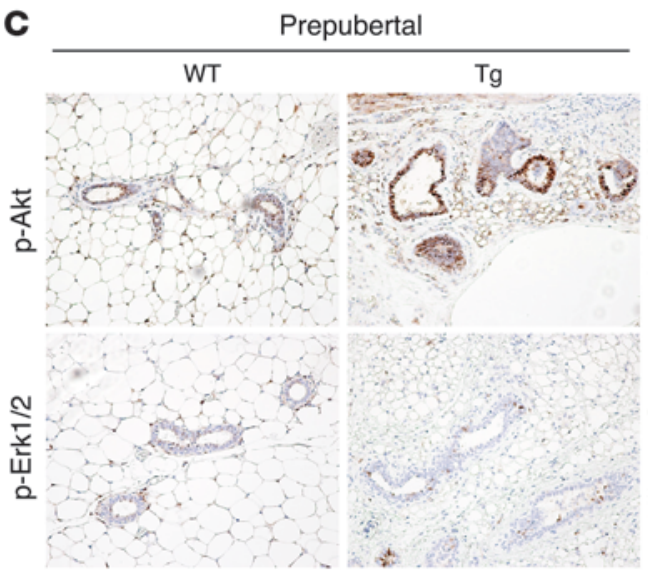

D
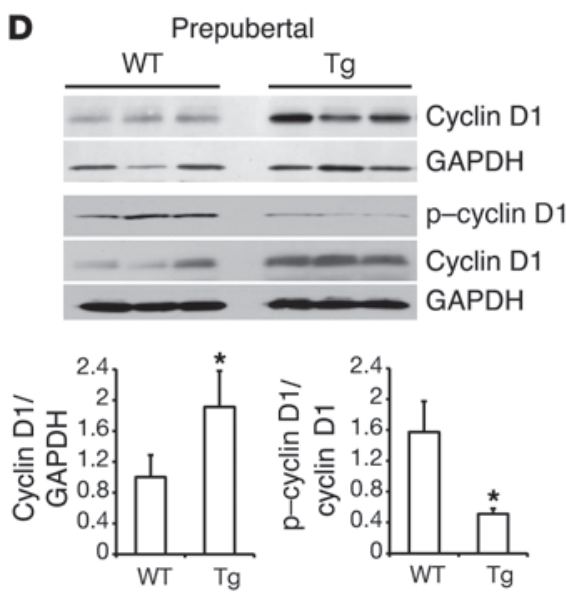

B
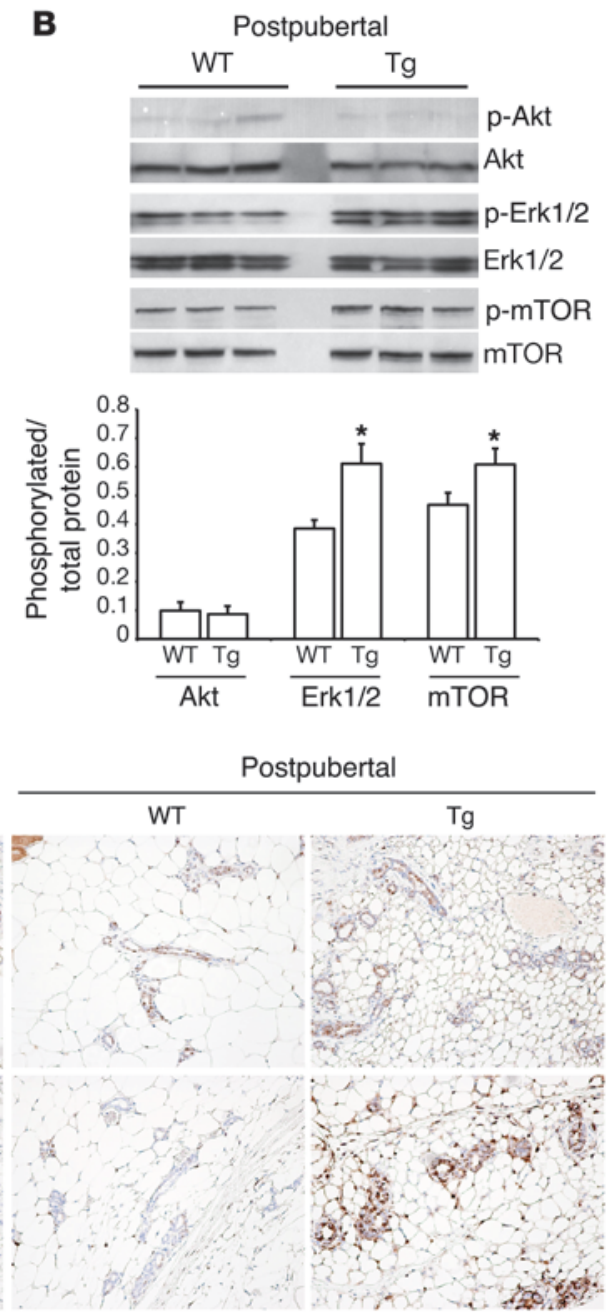

E
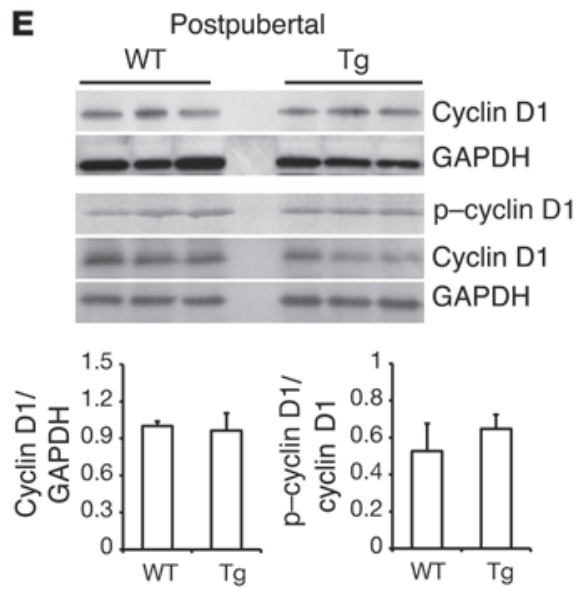

\section{Figure 1}

Detection of a developmentally dependent IGF-1 signal transduction pathway switch in mammary glands from Tg BK5.IGF-1 mice. Western blot analyses of total and phosphorylated Akt, mTOR, and Erk $1 / 2$ in mammary gland extracts from (A) prepubertal or (B) postpubertal BK5.IGF-1 Tg and WT mice, showing increased phosphorylation of Akt and mTOR in prepubertal $\mathrm{Tg}$ glands, and increased activation of Erk $1 / 2$ and $m T O R$ in postpubertal Tg glands. (C) Immunohistochemical localization of phosphorylated Akt and Erk1/2 in mammary glands from prepubertal and postpubertal WT and Tg mice (original magnification, $\times 20$ ). Western blot analysis of total and phosphorylated cyclin D1 expression in mammary glands from (D) prepubertal and (E) postpubertal mice, showing reduced phosphorylation of cyclin D1 at Thr286 in mammary glands from prepubertal, but not postpubertal, Tg mice compared with age-matched WT mice. Each lane represents pooled glands from 4-6 mice of the same age and genotype. Representative Western blots from 3 different pools per genotype/age are shown. Graphs present mean \pm SD of densitometric analysis of 5-6 different pools/lanes of each genotype and age. ${ }^{*} P<0.05$ versus age-matched WT mice, as determined by Student's $t$ test.
One mechanism of cyclin D1 regulation is ubiquitin-dependent degradation, which requires phosphorylation of a specific threonine residue (Thr286) (20). Using a specific antibody, we found that cyclin D1 phosphorylation at Thr286 was significantly reduced in prepubertal Tg glands compared with WT glands, but was similar in glands from postpubertal WT and Tg mice (Figure 1, $\mathrm{D}$ and $\mathrm{E})$. These results demonstrate that Tg IGF-1 increased cyclin D1 expression in prepubertal glands by inhibiting degradation.
Interestingly, cyclin D1 mRNA was not significantly elevated in Tg glands at either age (data not shown), indicating that regulation of cyclin D1 expression in this system occurs at the level of protein stability rather than transcription.

Activation of the proximal IGF-1 signaling pathways in mammary glands. To further investigate the apparent pathway switch, we analyzed tyrosine phosphorylation of key signaling proteins in glandular extracts from WT and Tg mice. Western blots showed an expected 
A

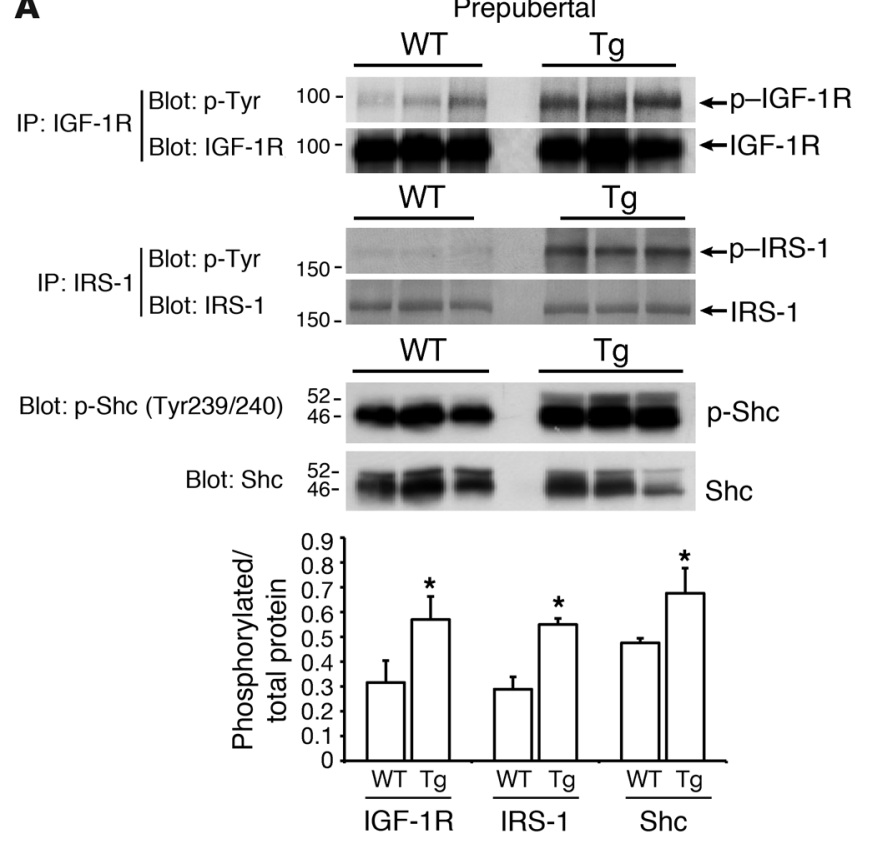

B
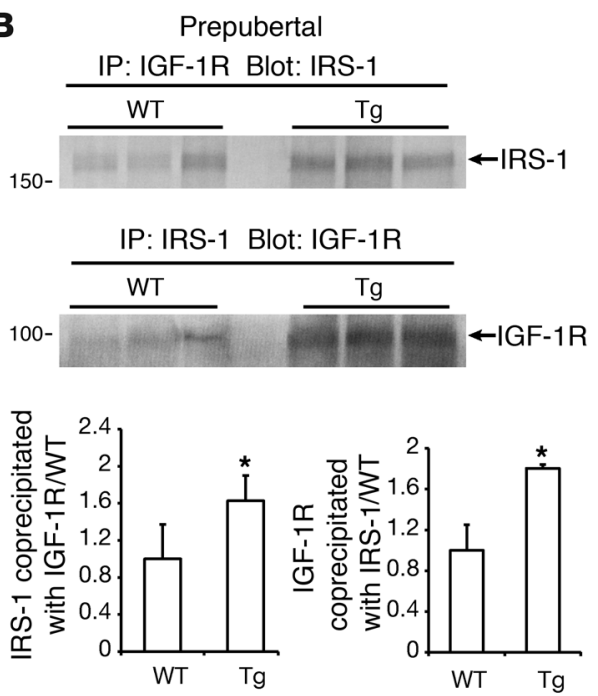

C
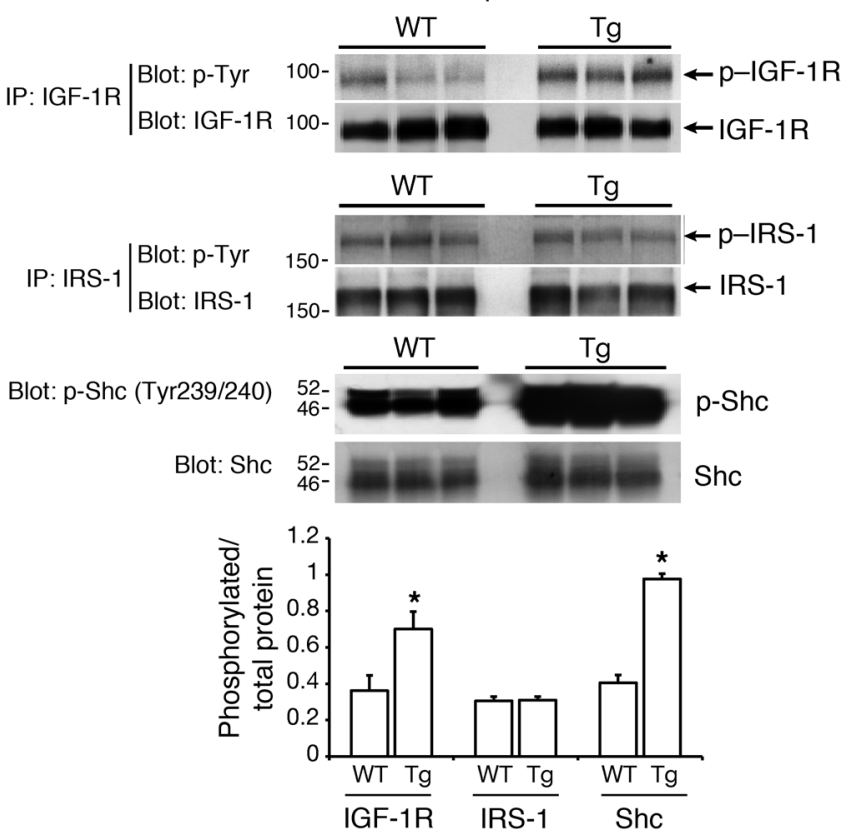

D
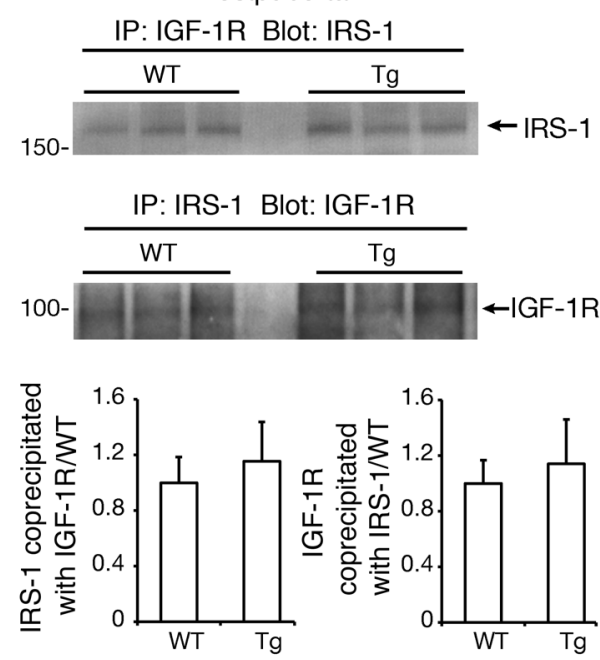

\section{Figure 2}

Different components of the proximal portion of the IGF-1 signaling pathway are activated in pre- and postpubertal Tg mammary glands. (A) Western blot analyses show increased tyrosine phosphorylation of IGF-1R ( $\beta$-subunit), IRS-1, and Shc in mammary gland extracts from prepubertal Tg mice compared with age-matched WT mice. (B) Western blots of mammary extracts, immunoprecipitated with either anti-IGF-1R or anti-IRS-1, showing increased formation of the IGF-1R/IRS-1 complex in prepubertal Tg compared with WT glands. The total IGF-1R and IRS-1 loading controls for these lanes are shown in the corresponding lanes in A. (C) Western blot analyses reveal increased tyrosine phosphorylation of IGF-1R and Shc, but not IRS-1, in glands from postpubertal Tg compared with WT mice. (D) IGF-1R/IRS-1 complex formation is not increased in postpubertal Tg compared with WT glands. The total IGF-1R and IRS-1 loading controls are shown in the corresponding lanes in C. Each lane represents pooled glands from 4-6 mice of the same age and genotype. Representative Western blots from 3 different pools per genotype/age are shown. Graphs present mean \pm SD of densitometric analysis of blots from $5-6$ different pools/lanes of each genotype and age. ${ }^{*} P<0.05$ versus age-matched WT mice, as determined by Student's $t$ test. 
A

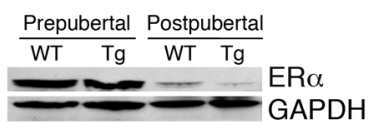

B

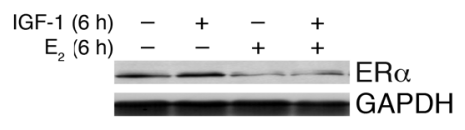

C

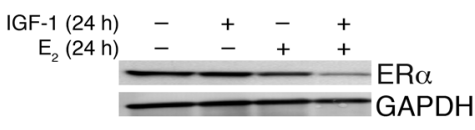

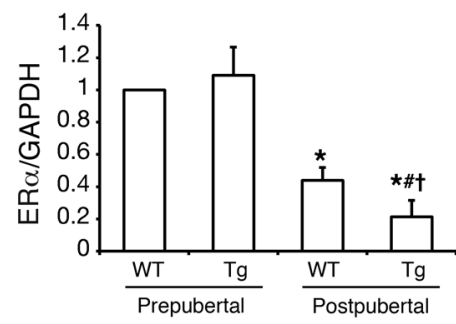

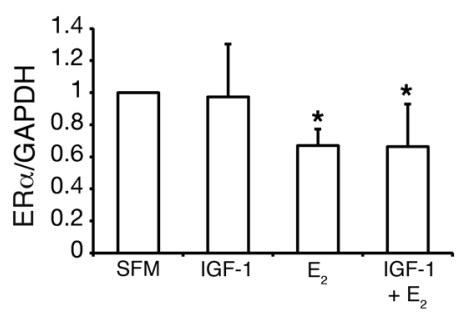

Figure 3

IGF-1 and $E_{2}$ affect ER $\alpha$ expression in vivo and in vitro. (A) Western blot analysis showing that the expression of ER $\alpha$ is reduced in mammary glands from postpubertal compared with prepubertal mice. ER $\alpha$ levels are further and significantly reduced in glandular extracts from postpubertal Tg mice compared with age-matched WT mice. Graphs present mean \pm SD of densitometric analyses of 4 independent experiments, with representative Western blots shown. ${ }^{*} P<0.05$ versus prepubertal WT; ${ }^{P} P<0.05$ versus prepubertal Tg; ${ }^{\dagger} P<0.05$ versus postpubertal WT as determined by Student's $t$ test. (B) In MCF-7 cells, ER $\alpha$ expression is reduced following 6 hours of treatment with either $10 \mathrm{nmol} / \mathrm{I} \mathrm{E}_{2}$ alone or with a combination of $40 \mathrm{ng} / \mathrm{ml} \mathrm{IGF-1} \mathrm{and} 10 \mathrm{nmol} / \mathrm{l} \mathrm{E}_{2}$ in SFM. (C) Also in MCF-7 cells, ER $\alpha$ levels are reduced following 24 hours of treatment with $E_{2}$ and further and significantly reduced by treatment with a combination of $E_{2}$ and IGF-1. ${ }^{*} P<0.05$ versus untreated cells; $\# P<0.05$ versus IGF- 1 -treated cells; ${ }^{\dagger} P<0.05$ versus $\mathrm{E}_{2}$-treated cells, as determined by Student's $t$ test.

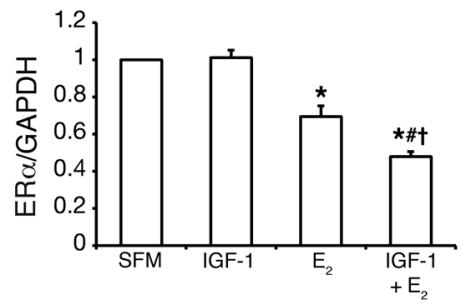

increase in tyrosine phosphorylation of IGF-1R in Tg glands from both pre- and postpubertal mice (Figure 2, A and C), indicating activation of the proximal portion of the signal transduction pathway in tissues from mice of both age groups. Activation of IRS- 1 and Shc was also increased in prepubertal Tg glands compared with WT glands (Figure 2A). Analysis of mammary glands from postpubertal animals, however, generated different results, reflective of the signaling pathway switch. While activated Shc was still elevated in postpubertal Tg compared with WT glands, IRS-1 phosphorylation was not increased (Figure 2C).

To further characterize the age dependence of IRS- 1 activation in response to Tg IGF-1, we examined formation of the IGF-1R/ IRS-1 complex in mammary gland extracts. As shown in Figure 2B, significantly more IRS-1 co-precipitated with IGF-1R in extracts from prepubertal $\mathrm{Tg}$ compared with WT glands. Similar results were achieved when the reverse procedure was used: extracts were first precipitated with an antibody to IRS-1, and blots were then probed with anti-IGF-1R. In contrast, Western blot analysis from postpubertal mammary glands showed no increase in formation of IGF-1R/IRS-1 complexes in glandular extracts from Tg compared with WT mice (Figure 2D). These results demonstrate that Tg IGF-1 induced formation of IGF-1R/IRS-1 complexes in mammary glands from prepubertal but not postpubertal animals.

Effects of IGF-1 and/or $E_{2}$ on ER $\alpha$ expression in vivo and in vitro. Results from these analyses indicated that a switch in the IGF-1 signal transduction pathway occurred coincidently with the change in endocrine milieu. As in vitro studies have reported crosstalk between the IGF- 1 and $\mathrm{E}_{2} / \mathrm{ER} \alpha$ signaling pathways (21-23), we then evaluated the involvement of ER $\alpha$ in IGF-1 signal transduction in vivo and began by assessing ER $\alpha$ expression in mammary glands. As shown in Figure 3A, the level of ER $\alpha$ expression was similar in the glands from prepubertal WT and Tg mice. A comparison of glandular extracts from different age groups showed that ER $\alpha$ expression levels were significantly reduced in postpubertal compared with prepubertal glands, which is in agreement with reports that $\mathrm{E}_{2}$ can downregulate expression of its cognate receptor in mammary cells in vitro $(24,25)$. Interestingly, results in Figure 3A also showed that ER $\alpha$ levels were more than 2-fold lower in postpubertal Tg compared with age-matched WT glands, indicating that the combination of elevated IGF-1 and $\mathrm{E}_{2}$ further downregulated receptor expression.

To explore further the synergistic action of IGF-1 and $\mathrm{E}_{2}$ in the mammary/breast epithelial milieu, we exposed serum-starved MCF-7 cells to IGF-1 with or without $\mathrm{E}_{2}$ for 6 or 24 hours. As shown in Figure 3, B and C, neither short- (6 hours) nor longterm (24 hours) treatment with IGF-1 alone downregulated ER $\alpha$ expression, but $\mathrm{E}_{2}$ treatment caused an approximately $30 \%$ reduction in the expression of the cognate receptor at both time points $(P<0.001$ and $P<0.001)$. After 6 hours of treatment, the effect of IGF-1 plus $E_{2}$ was the same as that of $E_{2}$ alone. However, 24 hours of treatment with IGF-1 plus $\mathrm{E}_{2}$ resulted in a significant downregulation of $\mathrm{ER} \alpha$ compared with $\mathrm{E}_{2}$ alone $(P<0.001)$. These in vitro data reflect the in vivo results, showing that IGF-1 alone had little effect on ER $\alpha$ expression, which reflects the situation in prepubertal Tg glands. Conversely, prolonged, combined exposure to IGF-1 plus $E_{2}$, which corresponds to the milieu in postpubertal $\mathrm{Tg}$ glands, resulted in significant reduction in ER $\alpha$ expression.

Addition of ER $\alpha$ to NMUMG cells induces a pathway switch and increases cyclin D1 expression in the presence of IGF-1. To determine whether changes in ER $\alpha$ expression levels played a role in IGF-1 pathway switch, we treated ER $\alpha$-negative, untransformed murine mammary epithelial (NMuMG) cells (26) with IGF-1 or vehicle, after transfection with a functional ER $\alpha$ expression vector ( $\mathrm{pRSV}-\mathrm{ER} \alpha$ ) or an "empty," control vector (pGL2 basic). Treatment of NMuMG cells with IGF-1 for 24 hours did not stimulate Akt phosphorylation, although a modest increase in Erk1/2 phosphorylation 
A

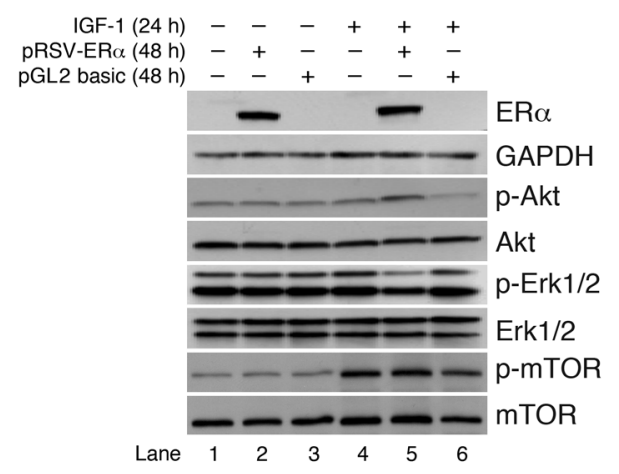

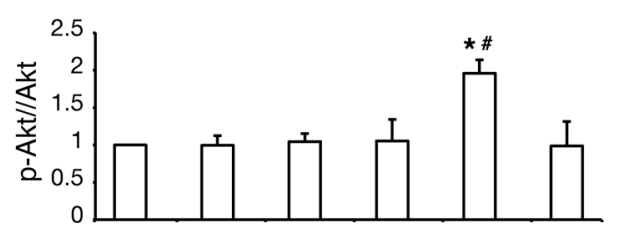
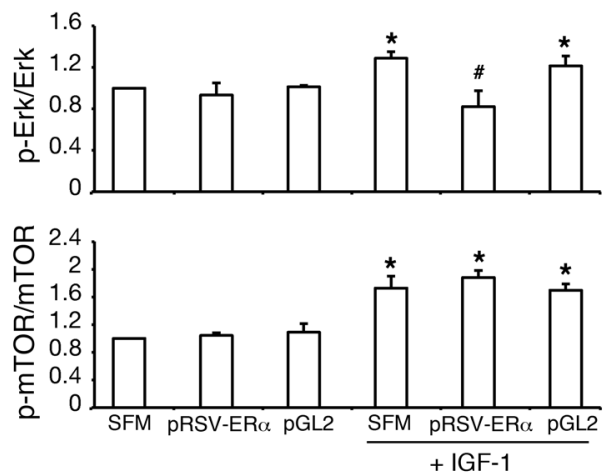

B

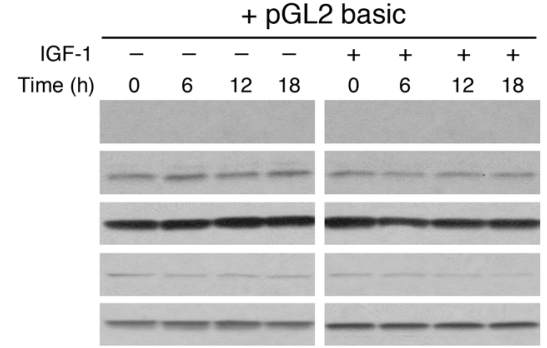

\begin{tabular}{cccccccc}
\multicolumn{1}{c}{+ pRSV-ER $\alpha$} \\
\hline- & - & - & - & + & + & + & + \\
0 & 6 & 12 & 18 & 0 & 6 & 12 & 18
\end{tabular}
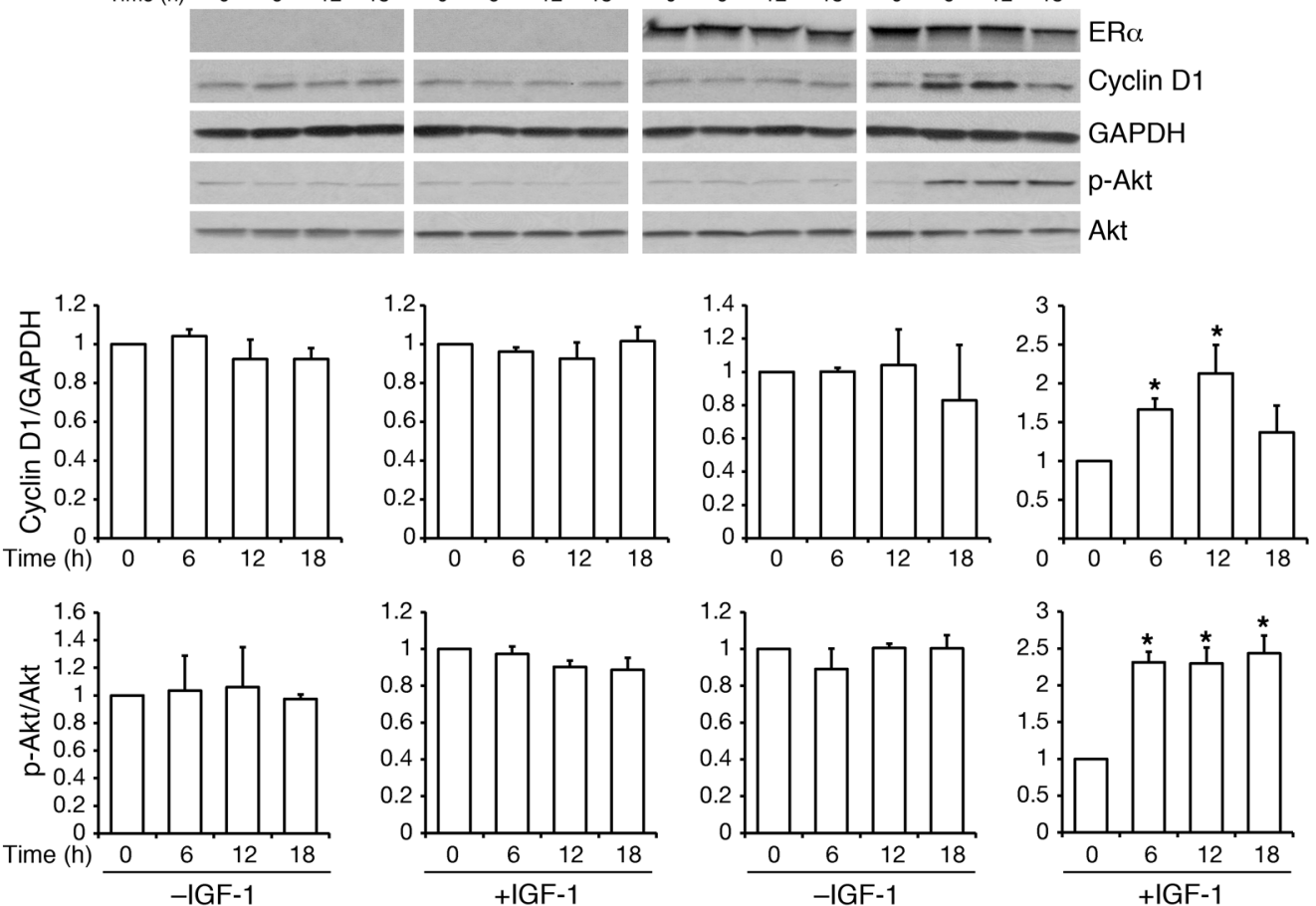

\section{Figure 4}

Expression of ER $\alpha$ in NMuMG cells induces a switch in the IGF-1-initiated signaling pathway that affects cyclin D1 expression. Treatment of NMuMG cells with either IGF-1 or vehicle, and transfection with a functional ER $\alpha$ expression vector ( $\mathrm{RRSV}-\mathrm{ER} \alpha)$ or the empty (control) vector (pGL2 basic), as described in Methods. (A) Western blot analysis shows that treatment with IGF-1 following transfection with pRSV-ER $\alpha$ results in increased phosphorylation of Akt and reduced phosphorylation of Erk1/2. ${ }^{\star} P<0.05$ versus untreated control cells in SFM; $\# P<0.05$ versus IGF-1-treated cells without transfected vector (SFM) or transfected with pGL2 basic (control) vector, as determined by ANOVA and Student's $t$ test. (B) Time course of the effects of IGF-1 treatment and transfection of ER $\alpha$ on cyclin D1 expression and Akt phosphorylation. Western blot analysis of cell extracts shows that treatment with $40 \mathrm{ng} / \mathrm{ml} \mathrm{IGF-1}$ and $p R S V-E R \alpha$ significantly increases cyclin D1 expression and phosphorylation of Akt by 6 hours. Graphs represent mean $\pm \mathrm{SD}$ of densitometric analysis of 3 independent Western blot experiments. A representative Western blot is shown. ${ }^{*} P<0.05$ versus 0 hours, as determined by ANOVA and Student's $t$ test. was detected (Figure 4A, lane 4). Following transfection of the pRSV-ER $\alpha$ expression vector, treatment with IGF-1 for 24 hours induced Akt phosphorylation, while Erk1/2 phosphorylation was reduced (Figure 4A, lane 5). Examination of the downstream targets revealed that IGF-1 increased phosphorylation of mTOR in either the presence or absence of ER $\alpha$ (Figure 4A, lanes 4-6), which agreed with our findings in mammary glands from preand postpubertal Tg and WT mice.

To further explore the involvement of ER $\alpha$ in mediating the biological effects of IGF-1, we also evaluated cyclin D1 expression. As shown in Figure 4B, when NMuMG cells were transfected with the pRSV-ER $\alpha$ expression vector, IGF-1 increased expression of cyclin D1 in a time-dependent manner, with a peak at 12 hours and return to baseline at 18 hours. Transfection of the empty vector (pGL2) in combination with IGF-1 treatment did not result in increased expression of cyclin D1 (Figure 4B). The decline in cyclin D1 levels after 12 hours may be a consequence of cell cycle progression, as reported by others $(27,28)$. Addition of IGF- 1 in the presence of $\mathrm{ER} \alpha$ also induced Akt phosphorylation within the same time frame, starting at 6 hours (Figure 4B) and extending through 18 hours (Figure 4, A and B).

These in vitro results reflect our in vivo findings in mammary glands from pre- and postpubertal Tg mice and demonstrate a causal relationship between the level of ER $\alpha$ expression and the 
A

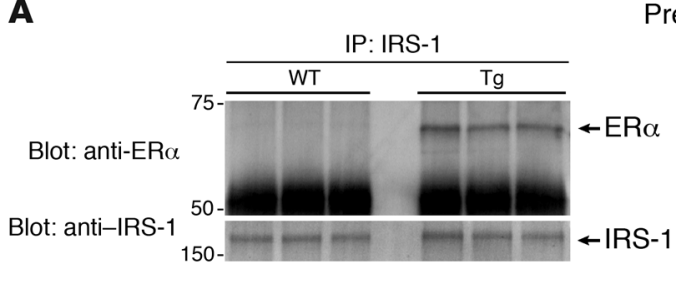

Prepubertal

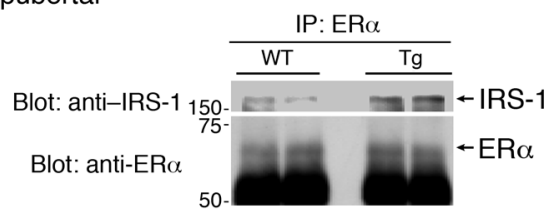

C

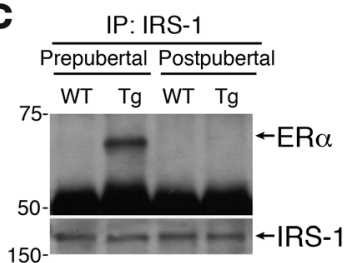

B

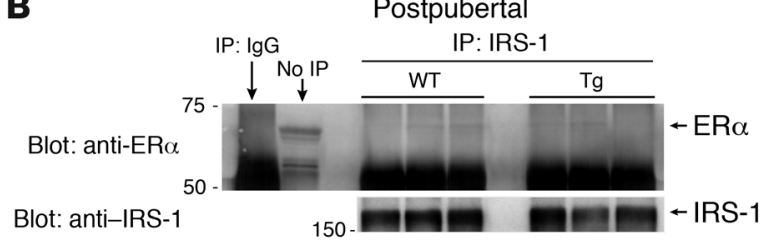

D
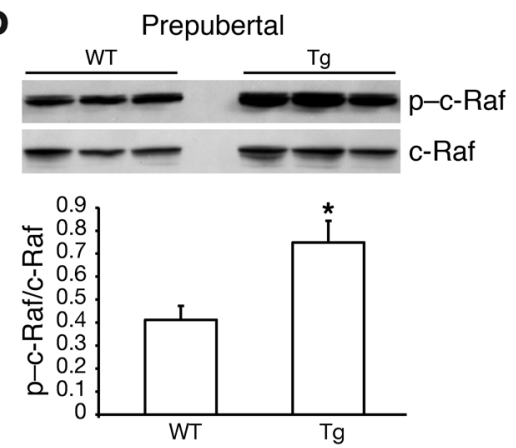

E

E
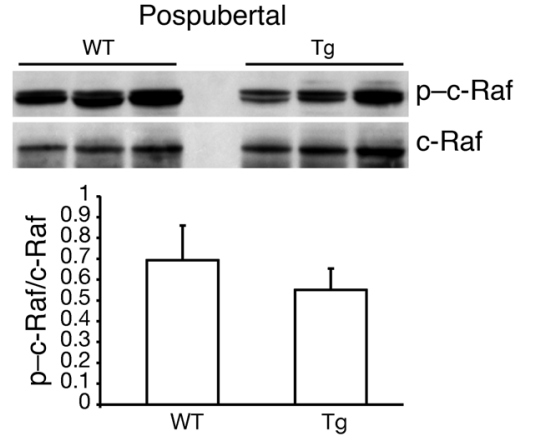

Figure 5

ER $\alpha$ expression levels determine the IGF-1 signal transduction pathway in the mammary gland. (A) Western blots of extracts from prepubertal mammary glands reveal increased formation of the ER $\alpha /$ IRS-1 complex, which can be immunoprecipitated with antibodies to either IRS-1 (left panel) or ER $\alpha$ (right panel). (B) Conversely, in extracts from postpubertal mammary glands, comparatively little $E R \alpha$ is co-precipitated with IRS-1 antibodies, indicating that complex formation is greatly reduced. (C) Side-by side comparison of anti-IRS-1 immunoprecipitates, showing that ER $\alpha / \mathrm{IRS}-1$ complexes are detected in glandular extracts from prepubertal $\mathrm{Tg}$ mice. In order to ultimately load equivalent amounts of total IRS-1, $250 \mu \mathrm{g}$ of glandular extracts from prepubertal mice and $500 \mu \mathrm{g}$ of extracts from postpubertal mice were incubated with anti-IRS-1. Western blot analysis of total and phosphorylated c-Raf (Ser259) in extracts of (D) prepubertal and (E) postpubertal Tg and WT mammary glands. Each lane represents pooled glands from 4-6 mice of the same age and genotype. Representative Western blots from 2-3 different pools per genotype and age are shown in A, B, D, and E. A representative Western blot of 3 independent experiments is shown in $\mathbf{C}$. Bar graphs in $\mathbf{D}$ and $\mathbf{E}$ represent mean \pm SD of densitometric analysis of blots from 5-6 different pools/lanes of each genotype and age. Statistical analysis performed using Student's $t$ test; ${ }^{*} P<0.05$, $\mathrm{p}-\mathrm{c}$-Raf/c-Raf ratio versus WT.

capacity of IGF-1 to activate signaling via the Akt pathway and to increase cyclin D1 and epithelial proliferation. As mTOR phosphorylation increased in glands from $\mathrm{Tg}$ mice at both ages, regardless of the level of ER $\alpha$ expression, it is unlikely that it is the critical mediator of the effects of the pathway switch on cyclin D1 expression and epithelial proliferation.

Increased ER $\alpha / I R S-1$ complex formation in prepubertal, but not postpubertal, Tg mammary glands. The results shown in Figure 2 suggest that ageassociated signaling changes were mediated, at least in part, by the proximal portion of the IGF-1 signaling pathway. Previously, Morelli et al. showed that ER $\alpha$ interacts with cytoplasmic IRS-1, thereby stabilizing it and amplifying IGF-1 signaling through the IRS-1/Akt pathway (29). Based on these in vitro findings, we hypothesized that the developmental variation in mammary ER $\alpha$ expression affected formation of the ER $\alpha /$ IRS- 1 complex, which, in turn, directed signal transduction and determined the ultimate tissue response.
Results in Figure 5, A and C, show that substantially more ER $\alpha /$ IRS- 1 complex was detected in mammary gland extracts from Tg prepubertal mice compared with age-matched WT mice. Conversely, little ER $\alpha$ was detected in IRS-1 immune complexes from postpubertal glands from WT or Tg mice (Figure 5, B and C). These data demonstrate that in the prepubertal period, when $\mathrm{E}_{2}$ levels were low and ER $\alpha$ levels were elevated in a compensatory manner, Tg IGF-1 induced formation of an ER $\alpha /$ IRS- 1 complex. Following the onset of ovarian hormone production at puberty, ER $\alpha$ expression was downregulated, causing a reduction in ER $\alpha /$ IRS- 1 complex formation and loss of Akt activation.

c-Raf phosphorylation in pre-and postpubertal mammary glands. A remaining question is why signaling via the Ras/Raf/MAPK pathway was inhibited in prepubertal glands, despite activation of Shc. Previous reports have indicated that activated Akt phosphorylates Ser259 of c-Raf, resulting in inhibition of signal transduction via this pathway (30, 31 ). We reasoned that c-Raf phosphorylation might contribute to the loss of MAPK activation observed in Tg prepubertal glands. To test this hypothesis, we examined phosphorylation of c-Raf at Ser259 in glands from mice in both age groups, using a site-specific antibody. As shown in Figure 5D, p-c-Raf levels increased in glands from prepubertal $\mathrm{Tg}$ mice compared with age-matched WT mice. Conversely, in mammary glands from $\mathrm{Tg}$ postpubertal animals, levels of $\mathrm{p}-\mathrm{c}$-Raf were not increased (Figure 5E). These results indicate that in mammary glands from prepubertal mice, Tg IGF-1 stimulated phosphorylation of Akt, which in turn induced phosphorylation of c-Raf, resulting in inhibition of signal transduction via the Raf/MAPK pathway and predominance of the PI3K/Akt pathway. In postpubertal tissues, c-Raf activation was not inhibited by Ser259 phosphorylation, thus permitting transduction via the MAPK pathway.

Analysis of mammary glands from mice that overexpress IGF-1 but lack $E R \alpha$. To further assess the role of ER $\alpha$ in IGF-1-mediated mammary development, proliferation, and signaling, we crossed BK5.IGF-1 Tg mice with ERKO mice (32) and evaluated the impact of transgenic IGF-1 overexpression in the absence and presence of ER $\alpha$ in vivo. These crosses generated mice of 4 genotypes: (a) IGF-1 WT/ER $\alpha$ WT (WT/WT), (b) IGF-1 WT/ ERKO (WT/KO), (c) BK5.IGF-1 Tg/ER $\alpha$ WT (Tg/WT), and (d) BK5.IGF-1 Tg/ERKO (Tg/KO). Mammary glands from 4- to 
A
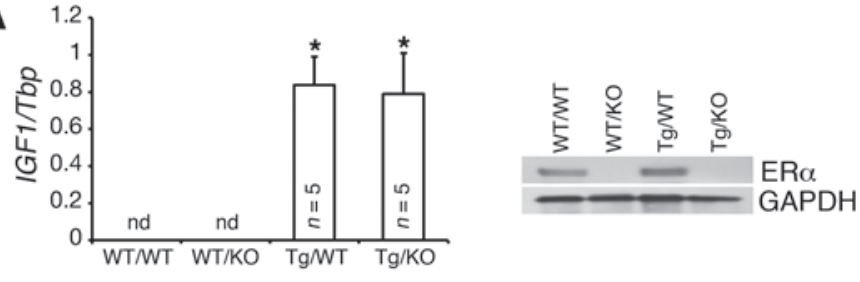

B
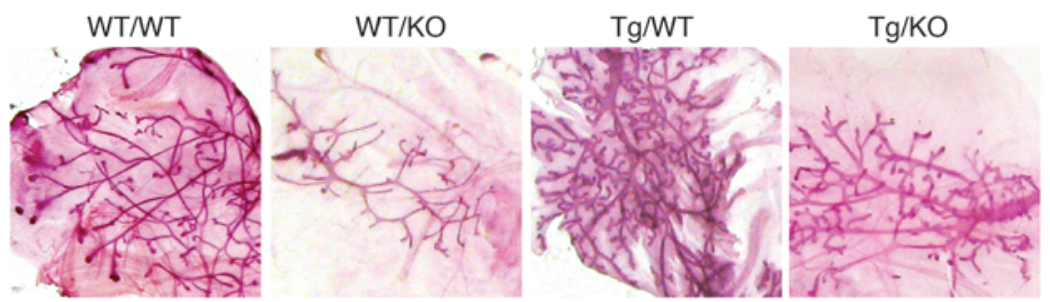

c
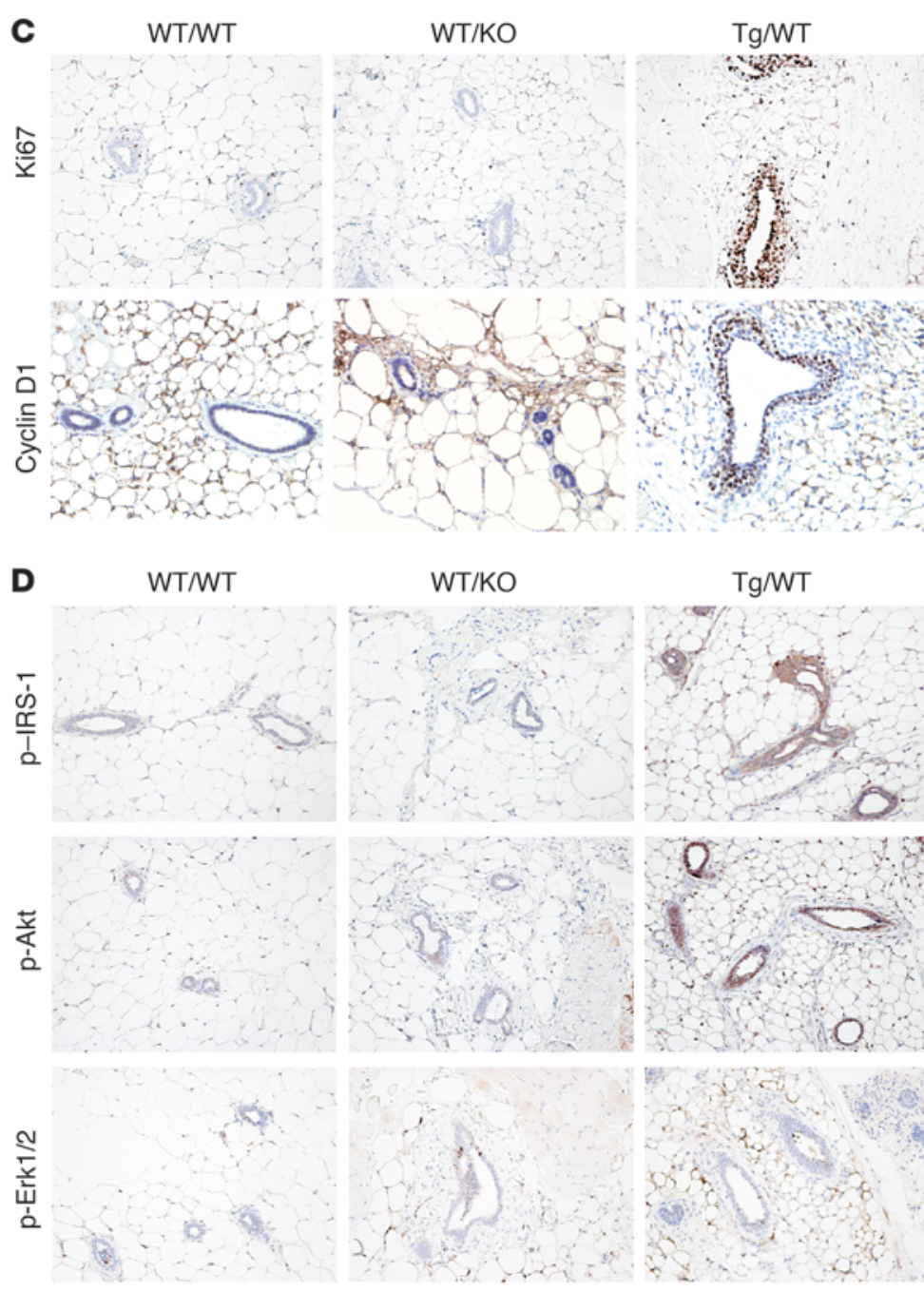
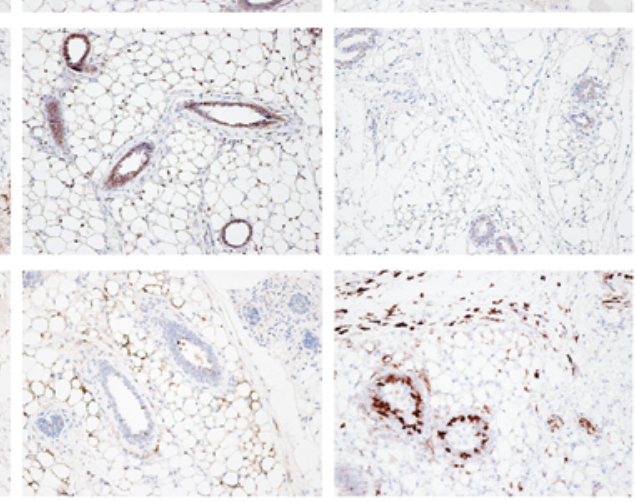

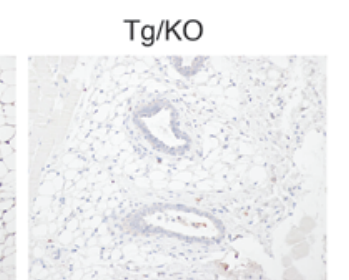

$\mathrm{Tg} / \mathrm{KO}$
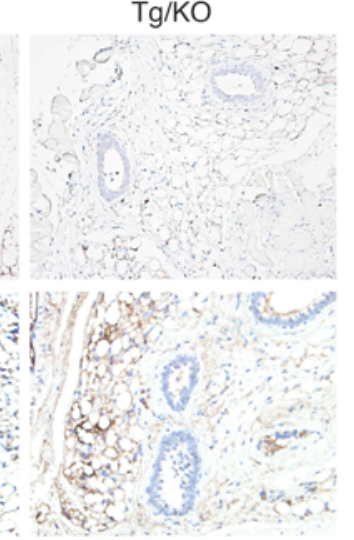

Figure 6

Analysis of mammary glands from 4- to 5-week-old bitransgenic BK5.IGF-1 $\times$ ERKO mice, which overexpress IGF-1 but lack ER $\alpha$. Crossing the two models generated mice of 4 genotypes, designated as follows: IGF-1 WT/ER $\alpha$ WT (WT/WT), IGF-1 WT/ERKO (WT/ KO), BK5.IGF-1 Tg/ER $\alpha$ WT (Tg/ WT), and BK5.IGF-1 Tg/ERKO $(\mathrm{Tg} / \mathrm{KO})$ mice. (A) Evaluation of transgene expression by qPCR (left panel) showing that human IGF1 is expressed exclusively in BK5.IGF-1 Tg mice. Western blot analysis of ER $\alpha$ expression shows that the receptor is not expressed in glands from ERKO mice (right panel). The bar graphs represent the mean \pm SD of separate experiments, as indicated by $n$ in the figure. Statistical analysis performed using Student's $t$ test; ${ }^{*} P<0.05$ versus WT/WT glands. (B) Representative whole mounts of mammary glands (original magnification, $\times 1$ ), showing that $\mathrm{Tg}$ IGF-1 does not rescue the ERKO phenotype. (C) Ki67 and cyclin D1 immunostaining in mammary glands from mice with each of the 4 bitransgenic genotypes (original magnification, $\times 20$ and $\times 40$, respectively), showing increased proliferation and cyclin D1 expression in the mammary epithelium of $\mathrm{Tg} / \mathrm{WT}$, but not $\mathrm{Tg} / \mathrm{KO}$, mice. (D) Immunohistochemical localization of p-IRS-1, p-Akt, and p-Erk1/2 in paraffin-embedded sections of mammary glands from mice with the 4 genotypes (original magnification, $\times 20$ ). nd, not detectable. 5-week-old female mice were harvested, and Tg IGF-1 and ER $\alpha$ expression was analyzed by quantitative PCR (qPCR) and Western blots, respectively. As shown in Figure 6A, there was no detectable human IGF1 mRNA in WT/WT or WT/KO mammary glands; however, IGF1 message was strongly expressed in Tg/WT and $\mathrm{Tg} / \mathrm{KO}$ mammary glands, demonstrating that crossing the
ERKO mice with the BK5.IGF-1 mice did not reduce expression of the transgene. As anticipated, ER $\alpha$ expression in WT/KO and $\mathrm{Tg} / \mathrm{KO}$ mammary glands was absent (Figure 6A). Thus, differences in mammary gland development, proliferation, and signaling could be attributed to the critical role of ER $\alpha$ and not to changes in IGF-1 transgene expression. 


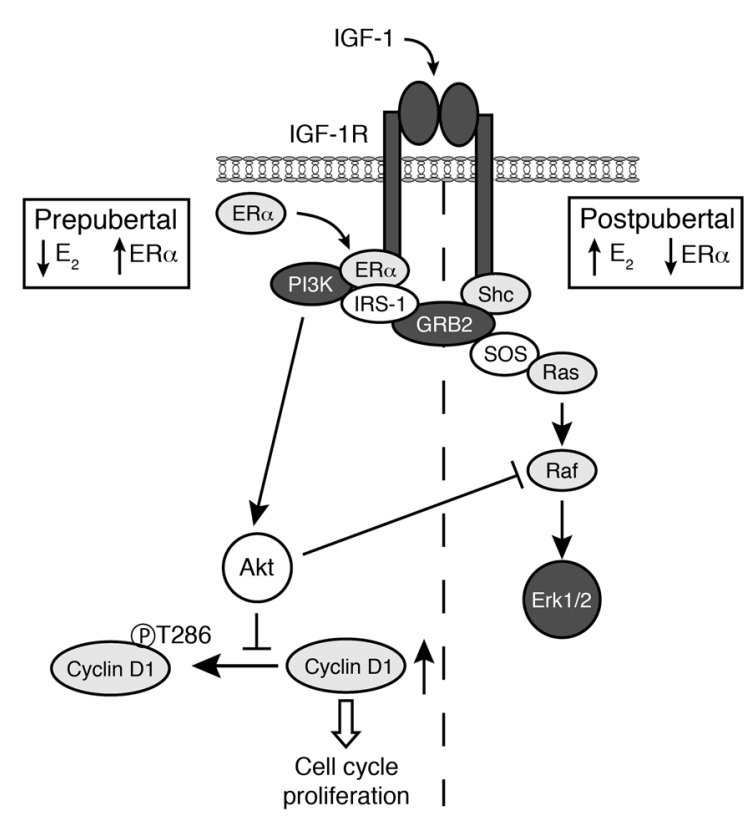

Whole mounts of mammary glands revealed that IGF-1 overexpression resulted in mammary gland hyperplasia in $\mathrm{Tg} / \mathrm{WT}$ mice, with increased ductal proliferation, cross-branching, alveolar end bud formation, and dilated ducts (Figure 6B), which is consistent with our previous report (14). Ductal development was substantially inhibited in ERKO mice (33). Glands from WT/KO and $\mathrm{Tg} / \mathrm{KO}$ mice showed a similar phenotype, with only rudimentary ductal development and few lobular alveoli, indicating that overexpression of IGF-1 did not rescue the ERKO mammary phenotype. These results suggest that ER $\alpha$ was required for both normal and IGF-1-induced ductal and alveolar morphogenesis.

To investigate cell proliferation in mammary glands from prepubertal mice of the 4 different genotypes, we performed immunohistochemical analysis of Ki67 incorporation. Mammary glands from Tg/WT mice showed increased Ki67 immunoreactivity in epithelial cells compared with WT/WT glands (Figure 6C). In contrast, $\mathrm{Ki} 67$ immunostaining was similar in glands from $\mathrm{Tg} / \mathrm{KO}$ mice and WT/KO mice, both of which had much lower levels of Ki67 expression than the glands from Tg/WT mice. The results indicate that DNA synthesis was not induced by IGF-1 in the absence of ER $\alpha$. Immunohistochemical analysis also showed that IGF-1-induced cyclin D1 expression was absent in $\mathrm{Tg} / \mathrm{KO}$ mice (Figure 6C), demonstrating that the proliferative response in mammary epithelium was ER $\alpha$ dependent.

Analysis of IRS-1, Akt, and Erk1/2 phosphorylation in mammary glands from mice of all 4 genotypes demonstrated the expected changes in signal transduction. In mammary glands from $\mathrm{Tg} / \mathrm{WT}$ mice, Tg IGF-1 increased the levels of p-IRS-1 and p-Akt in mammary epithelial cells, whereas the proportion of epithelial cells positive for $\mathrm{p}$-Erk1/2 was comparable in glands from $\mathrm{Tg} / \mathrm{WT}$ and WT/WT mice (Figure 6D). Conversely, p-Erk1/2 immunostaining was more intense in $\mathrm{Tg} / \mathrm{KO}$ compared with WT/WT glands, but there was no difference in intensity of p-IRS-1 and p-Akt staining (Figure 6D).

Taken together, the results from the crosses between the BK5. IGF-1 Tg and ERKO mice provide additional in vivo evidence that IGF-1-stimulated signaling and proliferation were determined by ER $\alpha$ expression levels. In the presence of ER $\alpha$, Tg IGF-1

\section{Figure 7}

Schematic diagram of IGF-1 signal transduction in mammary glands in vivo. In prepubertal glands, when $E_{2}$ levels are low and $E R \alpha$ levels are relatively high, IGF-1 stimulates the formation of ER $\alpha /$ IRS-1 complexes and activation of IRS-1, which directs signaling via the PI3K/Akt pathway. Activation of the PI3K/Akt pathway induces cyclin D1 expression and mammary epithelial proliferation. Cyclin D1 levels are regulated at the level of protein stability, through inhibition of Thr286 phosphorylation and ubiquitin-mediated degradation. Activation of the Akt pathway also induces phosphorylation of c-Raf, which inhibits transduction via the MAPK pathway. In postpubertal glands, ER $\alpha$ expression is downregulated in response to elevated $E_{2}$. In postpubertal Tg glands, the combination of IGF-1 and $E_{2}$ further reduces $E R \alpha$ levels. Due to this downregulation, ER $\alpha /$ IRS-1 complexes do not form, and the IRS-1/ $\mathrm{PI} 3 \mathrm{~K} /$ Akt pathway is not activated. However, Shc activation is maintained, allowing signal transduction via the MAPK pathway, which does not result in increased cyclin D1 expression or epithelial proliferation.

preferentially stimulated signaling via the IRS-1/PI3K/Akt pathway, resulting in increased cyclin D1 expression and epithelial proliferation. Conversely, when ER $\alpha$ levels were low or absent, IGF-1 signal transduction proceeded mainly through the MAPK pathway, which did not result in increased cyclin D1 expression or epithelial proliferation.

\section{Discussion}

Our previous work with the BK5.IGF-1 model revealed that overexpression of IGF-1 in the mammary gland induces hyperplasia of the mammary epithelium and increases susceptibility to spontaneous and DMBA-induced tumorigenesis (14). Surprisingly, our previous studies also showed that proliferative markers are elevated only in glands from prepubertal animals (14). Since this finding may have profound implications for understanding the role of IGF-1 in mammary tumorigenesis and identifying critical windows of enhanced susceptibility, we investigated the molecular bases of these unexpected results.

The signal transduction pathways downstream of IGF-1R are complex and have been studied extensively in cultured cells (34, $35)$. The overall consensus of these studies is that IGF-1R signals primarily through two major canonical pathways: IRS-1/PI3K/ Akt and Shc/Ras/MAPK. However, since the majority of previous studies were carried out in vitro, the relative importance of the Akt and MAPK pathways in mediating IGF-1 activity in tissues and the possible contributions of the endogenous endocrine milieu remain unresolved. In addition, while PI3K/Akt signaling has been widely implicated in IGF-1-induced mitogenesis $(36,37)$, our understanding of the role of MAPK in the induction of proliferative effects is still incomplete. Some studies demonstrate the importance of the MAPK pathway in inducing cyclin D1 expression (38). However, in MCF-7 cells, IGF-1-stimulated increases in cyclin D1 expression and cell cycle progression are inhibited by PI3K but not MEK1 (MAPK-activating kinase) inhibitors (39).

The importance of ER $\alpha$ in IGF-1-induced Akt pathway activation and proliferative responses has also been described in cell culture models, including some studies showing that IGF-1 and 
$\mathrm{E}_{2}$ have additive or synergistic effects on cellular proliferation (18, 40). These effects are usually attributed to functional crosstalk between $\mathrm{E}_{2} / \mathrm{ER} \alpha$ and IGF-1 systems, which includes potentiation of IGF- 1 responses by $E_{2}(23)$, stimulation of ER $\alpha$ activity by IGF-1 $(22,41)$, and additive activation of common signaling pathways $(21,42)$. While both IGF-1 and $\mathrm{E}_{2}$ reportedly stimulate expression of cyclin D1 and induce cell cycle progression, results in some systems indicate that the combined activities of IGF-1 and $E_{2}$ are required to achieve maximal expression $(18,43)$. However, conflicting results have also been reported. In lactotrophs in primary culture, simultaneous treatment with $\mathrm{E}_{2}$ markedly inhibits IGF-1induced proliferation (44), suggesting a level of tissue specificity in these responses. Recently, Cascio et al. showed that in MCF-7 cells, IGF-1-stimulated cyclin D1 mRNA expression is reduced in the presence of $E_{2}$ (45), which is reflective of our in vivo results.

Results presented here demonstrate that the activation of specific IGF-1 signaling pathways in mammary glands was dependent on the stage of development and the endogenous hormonal milieu. In prepubertal mice, IGF-1 overexpression stimulated signaling primarily via the PI3K/Akt pathway, leading to increased cyclin D1 expression in and elevated proliferation of mammary epithelium. At puberty, an apparent "switch" occurred, favoring activation of the MAPK pathway, which did not similarly stimulate increased cyclin D1 expression or proliferation.

The present findings also indicate that the increased cyclin D1 expression in tissues from prepubertal $\mathrm{Tg}$ animals was due to reduced degradation. The fact that $\mathrm{mTOR}$, which plays an important role in the translation of cyclin D1 mRNA $(46,47)$, was activated by Tg IGF-1 in both pre- and postpubertal mice, while cyclin D1 levels were only increased in prepubertal Tg glands, indicates that the regulation of cyclin D1 expression in this system was at the level of protein stability rather than synthesis. Further studies will be required to elucidate how signaling at different ages affects cyclin D1 protein turnover.

We speculated that the switch in the downstream IGF-1 signaling might be related to changes in ER $\alpha$ expression caused by the hormonal milieu, specifically by changes in the level of circulating reproductive hormones. Our in vivo experiments showed that ER $\alpha$ levels were relatively high in the mammary glands of the WT prepubertal mice and that paracrine overexpression of IGF-1 in the mammary gland did not reduce receptor expression. In postpubertal Tg glands, the combination of Tg IGF-1 and increased circulating levels of $E_{2}$ resulted in significantly reduced $E R \alpha$ expression. To test our hypothesis that ER $\alpha$ levels determined the IGF-1 signaling pathway, we carried out an in vitro study with ER $\alpha$-null NMuMG cells and an in vivo study utilizing bigenic BK5.IGF- $1 \times$ ERKO mice. Both studies demonstrated a causal relationship among ER $\alpha$ levels, IGF-1-induced Akt activation, and epithelial proliferation.

To explore the underlying molecular mechanisms, we investigated ER $\alpha /$ IRS- 1 complex formation. Our results showed that Tg IGF-1 stimulated formation of ER $\alpha /$ IRS- 1 complex only in the glands from prepubertal mice and that the complex was almost undetectable in postpubertal $\mathrm{Tg}$ glands. Formation of the ER $\alpha /$ IRS-1 complex has been reported to amplify the IGF-1 response through the IRS-1/PI3K/Akt pathway $(19,29)$, and our results show that ER $\alpha /$ IRS-1 complex formation controls both Akt activation and proliferation in the mammary gland. We also looked in vivo for an explanation for the lack of MAPK activation in the glands from prepubertal IGF-1 Tg mice, because Shc phosphorylation, known to initiate signaling via the MAPK pathway $(48,49)$, was elevated in these glands. Results showed that activation of the Akt pathway in prepubertal $\mathrm{Tg}$ glands resulted in an increase in c-Raf phosphorylation at Ser259, inhibiting transduction via the Ras/Raf/MAPK pathway. Conversely, in postpubertal Tg glands, activation of MAPK was maintained. Thus, the level of ER $\alpha$ expression in mammary glands indirectly regulates signaling via the MAPK pathway. A model based on these findings is presented in Figure 7.

These results identify critical, nongenomic actions of ER $\alpha$, previously unrecognized in vivo, that determine not only the predominant IGF-1 signal transduction pathway, but also the magnitude of the proliferative response to IGF-1 in the mammary gland. The lack of a proliferative response in glands from adult mice also has important ramifications for our understanding of the contributions of IGF-1 to mammary tumorigenesis. Previous results in the BK5.IGF-1 mouse and other models have shown that IGF-1 acts as a classical tumor promoter in the epidermis, where it stimulates increased proliferation following DMBA treatment $(17,50)$. However, in established mammary tumorigenesis protocols, DMBA treatment begins postpubertally, at 7-9 weeks of age (14). At this time, cyclin D1 and BrdU incorporation are no longer elevated in the mammary epithelium of Tg mice. Thus, increased susceptibility to mammary carcinogenesis in the BK5.IGF-1 model does not proceed through a classical tumor promotion mechanism.

Several alternate mechanisms can be speculated from these results. The most likely basis for increased tumor susceptibility is that the activation of the PI3K/Akt pathway in prepubertal glands induces increased ductal proliferation and accelerated mammary development, which also results in expansion of the number of carcinogen targets, possibly stem and/or progenitor cells (51). However, it cannot be ruled out that initiated or premalignant mammary epithelial cells responded to the proliferative effects of IGF-1 postpubertally but, due to their small numbers, were below the level of detection.

An alternate possibility is that signaling through the MAPK pathway in postpubertal glands is associated with other phenotypic alterations that contribute to mammary tumor development and progression, such as inflammation, enhanced vascularization, and/or other stromal changes (52). Interestingly, immunostaining of p-Erk $1 / 2$ increased in both the stromal and epithelial compartments of glands from bitransgenic BK5.IGF-1 $\mathrm{Tg} / \mathrm{ERKO}$ mice, supporting the contention that stromal activation also contributes to mammary tumorigenesis in this model. Further investigations into these hypothetical contributors to mammary carcinogenesis are ongoing.

Our results also provide insight into the contributions of IGF-1 to breast tumorigenesis over a lifetime. Although still somewhat controversial, epidemiological evidence indicates that exposure to high levels of IGF-1 may be a risk factor for breast, prostate, and colon cancer $(2,53)$. However, while it is well accepted that IGF-1 is a major contributor to breast cancer susceptibility (2), results from studies assessing serum IGF-1 levels in adult breast cancer patients have been conflicting $(54,55)$. These results may provide an explanation for the apparently discordant data regarding the role of IGF-1 in breast cancer and cancer risk. Most clinical and epidemiological studies measure circulating IGF-1 levels at the time of diagnosis, which, according to our results, is not the stage at which IGF-1 has the greatest pro-tumorigenic effects.

In addition, some studies have shown that African American women, who are significantly more likely to develop aggressive forms of breast cancer at an earlier age $(56,57)$, have serum IGF-1 levels comparable to or even lower than those in women of European 
descent $(58,59)$. Interestingly, studies consistently show that young African American girls have significantly higher circulating levels of IGF-1 in the pre- and perimenarchal periods, compared with agematched girls of European descent $(60,61)$. Results presented here indicate that elevated IGF-1 levels during early developmental periods, when ER $\alpha$ levels are relatively high, may be particularly important in determining breast cancer risk. Although speculative at this point, it is possible that early exposures to elevated levels of IGF-1 may contribute to the increased likelihood that African American women will develop aggressive, early-onset breast cancer.

These in vivo results also provide insight into the mechanisms underlying the generally accepted epidemiological findings that obesity, with the associated increases in free IGF-1, increases breast cancer risk in postmenopausal women (62-66). It is well established that after menopause, levels of ER $\alpha$ are again elevated in breast epithelium $(67,68)$. Our current results indicate that the combination of increased ER $\alpha$ expression and elevated IGF-1 induced a highly proliferative mammary epithelium, which substantially increased risk.

In summary, these studies demonstrate the value of combining in vitro and in vivo models in elucidating the mechanisms of IGF-1-stimulated mammary tumorigenesis. The results show that ER $\alpha$ expression levels are a major determinant of the activation of IGF-1-dependent signaling pathways and pro-tumorigenic proliferation in the mammary gland. Our investigations also identified an important contribution of nongenomic actions of ER $\alpha$ on tumor promotion and demonstrated that early exposures to elevated IGF-1 contributed to lifetime risk. These findings are critical for elucidating the factors that contribute to breast cancer susceptibility. Results also indicate that potential preventive strategies involving modulation of diet and energy balance may need to be focused not only on post-menopausal women, but also on young and adolescents girls.

\section{Methods}

Mice. BK5.IGF-1 Tg and ERKO mice and their characterization were previously described $(14,17,32)$. BK5.IGF-1 Tg mice were maintained on an ICR background and were hemizygous for the transgene. Homozygous ERKO mice were on a C57BL/6J background. Mice were genotyped by genomic PCR using the following primers: forward primer for detection of WT ER $\alpha$ gene, 5'-CGGTCTACGGCCAGTCGGGCATC-3'; forward primer for determination of Neo disruption of ER $\alpha$ gene, $5^{\prime}$-GCTGACCGCTTCCTCGTGCTTTAC-3'; reverse primer for both, 5' -CAGGCCTTACACAGCGGCCACCC- $3^{\prime}$. Only female mice were used. All controls were age-matched mice of the same generation and background. All mice were fed standard chow ad libitum with free access to water and housed in our Association for Assessment and Accreditation of Laboratory Animal Carecertified (AAALAC-certified), temperature- and humidity-controlled facilities, with a 12-hour light/12-hour dark cycle. All procedures were in strict accordance with protocols approved by the IACUC of the M.D. Anderson Cancer Center. Mice were sacrificed by $\mathrm{CO}_{2}$ asphyxiation. In ICR mice, mammary glands were collected from WT and Tg mice at 4-5 weeks (prepubertal) or 8-13 weeks of age (postpubertal). In crossbred strains, glands were collected at 4-5 weeks of age (prepubertal).

Cell culture. MCF-7 and NMuMG cells were obtained from ATCC and maintained in phenol red-free DMEM (HyClone) supplemented with $10 \% \mathrm{FBS}, 10 \mathrm{mM}$ sodium pyruvate, and $3.7 \mathrm{~g} / \mathrm{l}$ sodium bicarbonate. The expression plasmid for wild-type ER $\alpha$ (pRSV-ER $\alpha$ ) was provided by Mark Bedford (University of Texas M.D. Anderson Cancer Center; ref. 69). For IGF-1 and $\mathrm{E}_{2}$ treatments, MCF-7 cells were serum starved and maintained in serum- and phenol red-free medium (SFM) overnight and then treated with IGF-1 (40 ng/ml; Sigma-Aldrich), E (10 nmol/l; Sigma-Aldrich), or IGF-1 plus $\mathrm{E}_{2}$ for 6 or 24 hours. For transient transfection, NMuMG cells were plated in 6 -well plates until $80 \%$ confluent. The cells were then transfected with $6 \mathrm{~g}$ of ER $\alpha$ plasmid using Lipofectamine 2000 (Invitrogen) in SFM according to the manufacturer's instructions. The pGL2 basic vector (E1611) was used as negative control (Promega). Twenty-four hours after the start of transfection, cell culture medium was replaced with fresh SFM, and $40 \mathrm{ng} / \mathrm{ml}$ IGF-1 or control vehicle was added to the medium. The cells were harvested at 24 hours to detect Akt, Erk1/2, and mTOR phosphorylation or between 0 and 18 hours to examine cyclin D1 expression and Akt activation, as indicated in figure legends.

Western blot analysis. Frozen abdominal/inguinal mammary glands from 4-6 mice were pooled and homogenized in extraction buffer (10 mM HEPES [pH 7.9], $0.4 \mathrm{M} \mathrm{NaCl}, 0.1 \mathrm{mM}$ EDTA, $5 \%$ glycerol, $0.02 \mathrm{mM} \mathrm{Na}_{3} \mathrm{VO}_{4}$, and protease inhibitors), and cells were lysed with RIPA buffer (50 mM Tris$\mathrm{HCl}$ [pH 7.4], 1\% NP-40, 0.25\% sodium deoxycholate, $150 \mathrm{mM} \mathrm{NaCl}, 1 \mathrm{mM}$ EDTA, $1 \mathrm{mM}$ PMSF, $1 \mathrm{mM} \mathrm{Na}_{3} \mathrm{VO}_{4}$, and $1 \mathrm{mM} \mathrm{NaF}$ ) as described previously $(14,70)$. Protein concentrations were determined using the BCA protein assay kit (Pierce). Equal amounts of protein $(40 \mu \mathrm{g})$ were resolved by SDSPAGE and transferred to PVDF membranes (Pierce). The membranes were then immunoblotted with specific antibodies. Rabbit polyclonal antibodies against IGF-1R $\beta$, IRS-1, phosphorylated Akt (Ser473), Akt, phosphorylated Erk1/2 (Thr202/Tyr204), Erk1/2, phosphorylated mTOR (Ser2448), mTOR, phosphorylated cyclin D1 (Thr286), phosphorylated c-Raf (Ser259), c-Raf, rabbit monoclonal antibody to GAPDH, and mouse monoclonal antibody to cyclin D1 were purchased from Cell Signaling Technology. Rabbit polyclonal antibody to ER $\alpha$ was purchased from Zymed Laboratories (Invitrogen). Mouse monoclonal antibodies against phosphorylated She (Tyr239/240) and Shc were obtained from Santa Cruz Biotechnology Inc. The blot was then incubated with appropriate HRP-conjugated secondary antibody, and bands were detected using the ECL Plus kit (Amersham, GE Healthcare). The intensities of the bands were scanned with Typhoon (Typhoon 9410, GE Healthcare) and quantified by densitometry using ImageQuant TL software (Amersham Biosciences), and the ratio between phosphorylated and total proteins, or target and housekeeping proteins, was calculated.

Immunoprecipitation. Protein lysates ( $500 \mu \mathrm{g})$ (unless specifically indicated) from glands were incubated overnight at $4^{\circ} \mathrm{C}$ with antibodies to IGF-1R $\beta$ (1:100), IRS-1 (1:50), ER $\alpha$ (1:25), or nonimmune rabbit IgG (1:50) and then incubated with $40 \mu \mathrm{l}$ protein $\mathrm{A} / \mathrm{G}$ agarose (Pierce) for 2 hours at room temperature. The resulting immune complexes were resolved by SDS-PAGE and immunoblotted with antibodies to phosphotyrosine (PY20; Santa Cruz Biotechnology Inc.), IGF-1R $\beta$, IRS-1, or ER $\alpha$ as indicated.

Whole mounts. Cervical glands were harvested, pressed between glass slides, and fixed in Carnoy's fixative (100\% ethanol, chloroform, and glacial acetic acid at a 6:3:1 ratio) for 2-4 hours. After being hydrated in 70\% ethanol and distilled water, slides were stained overnight in carmine alum ( $0.2 \%$ carmine, $0.5 \%$ aluminum potassium sulfate). The tissues were then dehydrated in graded ethanols and xylene substitute, washed, and stored in fresh PBS until photographs were taken.

Immunohistochemistry. Paraffin-embedded sections of thoracic glands were pretreated with $10 \mathrm{mmol} / \mathrm{l}$ citrate buffer ( $\mathrm{pH}$ 6.0) for 10 minutes for detection of Ki67, cyclin D1, p-IRS-1, and p-Akt in mammary glands, or with $1 \times$ Tris-EDTA buffer ( $\mathrm{pH}$ 9.0) for 20 minutes to determine $\mathrm{p}$-Erk1/2 expression. Slides were then incubated with antibodies to Ki67 (1:100; Santa Cruz Biotechnology Inc.), p-IRS-1 (Tyr632; 1:100; Santa Cruz Biotechnology Inc.), p-Akt (Ser473; 1:250; Santa Cruz Biotechnology Inc.), and p-Erk1/2 (Thr202/Tyr204; 1:200; Cell Signaling Technology) at $4{ }^{\circ} \mathrm{C}$ overnight followed by HRP-linked anti-rabbit IgG (Dako), or with an antibody to cyclin D1 (1:1,000; Cell Signaling Technology) for 1 hour at room 
temperature followed by HRP-linked anti-mouse IgG (Dako). Color was developed with 3,3'-diaminobenzidene (Dako).

$R N A$ extraction and real-time $q P C R$. Total RNA from homogenized abdominal/ inguinal glands was extracted with an Absolutely RNA Miniprep Kit (Agilent Technologies) and reverse transcribed as previously described (14). Real-time qPCR was performed using the ABI Prism $7900 \mathrm{HT}$ sequence detection system (Applied Biosystems). Primers and probe for human IGF-1 were obtained from Applied Biosystems TaqMan gene expression assays. The TATA box binding protein (TBP) primers and probe used were as follows: forward primer, $5^{\prime}$-GGTGGCAGCATGAAGTGACA-3'; reverse primer, 5'-GCACAGAGCAAGCAACTCACA-3'; TaqMan probe, 5'-FAM-CCTCTGCACTGAAATCACCTGCAGCATAMRA- $3^{\prime}$. Target gene expression of each sample was normalized to its corresponding TBP gene value. A relative standard curve was generated for each assay using the whole mammary gland from a young, untreated WT mouse. The Ct (threshold cycle) of each sample was plotted against the log of nanograms of cDNA added to the wells of the standard curve, and the reverse $\log$ of that number was normalized to its corresponding TBP value.

Statistics. Numerical results are shown as mean \pm SD. Two-tailed Student's $t$ test was used to compare results from 2 experimental groups. ANOVA was used when data from multiple groups were studied. $P<0.05$ was considered to indicate a significant different between comparison groups.

\section{Acknowledgments}

The work was supported by NIH/National Institute of Environmental Health Sciences (NIEHS) Center grant ES07784, NIH/ National Cancer Institute grants CA16672 (Cancer Center Support Grant) and CA104114 (to R. Fuchs-Young), and US Army Medical Research and Material Command grant DAMD17-01-0303 (to J. Tian). We thank Noirin Cullinan-Ammann for assistance with animal maintenance. We also thank Joyce E. Rundhaug for advice and thoughtful comments on the manuscript.

Received for publication December 31, 2009, and accepted in revised form November 2, 2011.

Address correspondence to: Robin Fuchs-Young, the University of Texas M.D. Anderson Cancer Center, Science Park Research Division, P.O. Box 389, Smithville, Texas 78957, USA. Phone: 512.237.9547; Fax: 512.237.6440; E-mail: rfyoung@mdanderson.org.

John DiGiovanni's present address is: Department of Pharmacology and Toxicology, Dell Pediatric Research Institute, The University of Texas at Austin, Austin, Texas, USA.
1. Yee D. The insulin-like growth factors and breast cancer - revisited. Breast Cancer Res Treat. 1998 ; 47(3):197-199.

2. Yu H, Rohan T. Role of the insulin-like growth factor family in cancer development and progression. J Natl Cancer Inst. 2000;92(18):1472-1489.

3. Valentinis B, Baserga R. IGF-I receptor signalling in transformation and differentiation. Mol Pathol. 2001;54(3):133-137.

4. Vivanco I, Sawyers CL. The phosphatidylinositol 3-Kinase AKT pathway in human cancer. Nat Rev Cancer. 2002;2(7):489-501.

5. White MF, Yenush L. The IRS-signaling system: a network of docking proteins that mediate insulin and cytokine action. Curr Top Microbiol Immunol. 1998;228:179-208.

6. White MF. The IRS-signalling system: a network of docking proteins that mediate insulin action. $\mathrm{Mol}$ Cell Biochem. 1998;182(1-2):3-11.

7. Goalstone ML, Draznin B. What does insulin do to Ras? Cell Signal. 1998;10(5):297-301.

8. Hay N. The Akt-mTOR tango and its relevance to cancer. Cancer Cell. 2005;8(3):179-183.

9. Luo J, Manning BD, Cantley LC. Targeting the PI3K-Akt pathway in human cancer: rationale and promise. Cancer Cell. 2003;4(4):257-262.

10. Vanhaesebroeck B, Alessi DR. The PI3K-PDK1 connection: more than just a road to PKB. Biochem J. 2000;346(pt 3):561-576.

11. Creighton CJ, et al. Insulin-like growth factor-I activates gene transcription programs strongly associated with poor breast cancer prognosis. J Clin Oncol. 2008;26(25):4078-4085.

12. Mu L, et al. Peptide concentrations and mRNA expression of IGF-I, IGF-II and IGFBP-3 in breast cancer and their associations with disease characteristics. Breast Cancer Res Treat. 2009;115(1):151-162.

13. Shin A, Ren Z, Shu XO, Cai Q, Gao YT, Zheng W. Expression patterns of insulin-like growth factor 1 (IGF-I) and its receptor in mammary tissues and their associations with breast cancer survival. Breast Cancer Res Treat. 2007;105(1):55-61.

14. de Ostrovich KK, et al. Paracrine overexpression of insulin-like growth factor- 1 enhances mammary tumorigenesis in vivo. Am J Pathol. 2008; 173(3):824-834.

15. Hadsell DL, Greenberg NM, Fligger JM, Baumrucker CR, Rosen JM. Targeted expression of des(1-3) human insulin-like growth factor I in transgenic mice influences mammary gland development and IGF-binding protein expression. Endocrinology. 1996;137(1):321-330.

16. Weber MS, Boyle PL, Corl BA, Wong EA, Gwazdauskas FC, Akers RM. Expression of ovine insulin-like growth factor-1 (IGF-1) stimulates alveolar bud development in mammary glands of transgenic mice. Endocrine. 1998;8(3):251-259.

17. DiGiovanni J, et al. Constitutive expression of insulin-like growth factor- 1 in epidermal basal cells of transgenic mice leads to spontaneous tumor promotion. Cancer Res. 2000;60(6):1561-1570.

18. Dupont J, Karas M, LeRoith D. The potentiation of estrogen on insulin-like growth factor I action in MCF-7 human breast cancer cells includes cell cycle components. J Biol Chem. 2000;275(46):35893-35901.

19. Sisci D, Surmacz E. Crosstalk between IGF signaling and steroid hormone receptors in breast cancer. Curr Pharm Des. 2007;13(7):705-717.

20. Diehl JA, Zindy F, Sherr CJ. Inhibition of cyclin D1 phosphorylation on threonine-286 prevents its rapid degradation via the ubiquitin-proteasome pathway. Genes Dev. 1997;11(8):957-972.

21. Surmacz E, Bartucci M. Role of estrogen receptor alpha in modulating IGF-I receptor signaling and function in breast cancer. J Exp Clin Cancer Res. 2004;23(3):385-394.

22. Lee AV, Weng CN, Jackson JG, Yee D. Activation of estrogen receptor-mediated gene transcription by IGF-I in human breast cancer cells. J Endocrinol. 1997;152(1):39-47.

23. Kahlert S, Nuedling S, van Eickels M, Vetter $H$ Meyer R, Grohe C. Estrogen receptor alpha rapidly activates the IGF-1 receptor pathway. J Biol Chem. 2000;275(24):18447-18453.

24. Nawaz Z, Lonard DM, Dennis AP, Smith CL, O'Malley BW. Proteasome-dependent degradation of the human estrogen receptor. Proc Natl Acad Sci US A. 1999;96(5):1858-1862.

25. Chu I, et al. Src promotes estrogen-dependent estrogen receptor alpha proteolysis in human breast cancer. J Clin Invest. 2007;117(8):2205-2215.

26. Jalkanen M, Nguyen H, Rapraeger A, Kurn N, Bernfield M. Heparan sulfate proteoglycans from mouse mammary epithelial cells: localization on the cell surface with a monoclonal antibody. J Cell Biol. 1985;101(3):976-984.

27. Sherr CJ. D-type cyclins. Trends Biochem Sci. 1995; 20(5):187-190.

28. Rodriguez-Puebla ML, LaCava M, Conti CJ. Cyclin D1 overexpression in mouse epidermis increases cyclin-dependent kinase activity and cell proliferation in vivo but does not affect skin tumor development. Cell Growth Differ. 1999;10(7):467-472.

29. Morelli C, Garofalo C, Bartucci M, Surmacz E. Estrogen receptor-alpha regulates the degradation of insulin receptor substrates 1 and 2 in breast cancer cells. Oncogene. 2003;22(26):4007-4016.

30. Zimmermann S, Moelling K. Phosphorylation and regulation of Raf by Akt (protein kinase B). Science. 1999;286(5445):1741-1744.

31. Rommel C, et al. Differentiation stage-specific inhibition of the Raf-MEK-ERK pathway by Akt. Science. 1999;286(5445):1738-1741.

32. Lubahn DB, Moyer JS, Golding TS, Couse JF, Korach $\mathrm{KS}$, Smithies O. Alteration of reproductive function but not prenatal sexual development after insertional disruption of the mouse estrogen receptor gene. Proc Natl Acad Sci U S A. 1993;90(23):11162-11166.

33. Bocchinfuso WP, et al. Induction of mammary gland development in estrogen receptor-alpha knockout mice. Endocrinology. 2000;141(8):2982-2994.

34. Jackson JG, White MF, Yee D. Insulin receptor substrate- 1 is the predominant signaling molecule activated by insulin-like growth factor-I, insulin, and interleukin-4 in estrogen receptor-positive human breast cancer cells. J Biol Chem. 1998;273(16):9994-10003.

35. Coolican SA, Samuel DS, Ewton DZ, McWade FJ, Florini JR. The mitogenic and myogenic actions of insulin-like growth factors utilize distinct signaling pathways. J Biol Chem. 1997;272(10):6653-6662.

36. Toker A. Protein kinases as mediators of phosphoinositide 3-kinase signaling. Mol Pharmacol.2000; 57(4):652-658.

37. Muise-Helmericks RC, Grimes HL, Bellacosa A, Malstrom SE, Tsichlis PN, Rosen N. Cyclin D expression is controlled post-transcriptionally via a phosphatidylinositol 3-kinase/Akt-dependent pathway. J Biol Chem. 1998;273(45):29864-29872.

38. Diehl JA. Cycling to cancer with cyclin D1. Cancer Biol Ther. 2002;1(3):226-231.

39. Dufourny B, et al. Mitogenic signaling of insulinlike growth factor I in MCF-7 human breast cancer cells requires phosphatidylinositol 3-kinase and is independent of mitogen-activated protein kinase. J Biol Chem. 1997;272(49):31163-31171.

40. Dupont J, Le Roith D. Insulin-like growth factor 1 and oestradiol promote cell proliferation of MCF-7 breast cancer cells: new insights into their synergistic effects. Mol Pathol. 2001;54(3):149-154.

41. Yee D, Lee AV. Crosstalk between the insulin-like 
growth factors and estrogens in breast cancer. J Mammary Gland Biol Neoplasia. 2000;5(1):107-115.

42. Foster JS, Henley DC, Ahamed S, Wimalasena J. Estrogens and cell-cycle regulation in breast cancer. Trends Endocrinol Metab. 2001;12(7):320-327.

43. Hamelers IH, van Schaik RF, Sipkema J, Sussenbach JS, Steenbergh PH. Insulin-like growth factor I triggers nuclear accumulation of cyclin D1 in MCF-7S breast cancer cells. J Biol Chem. 2002; 277(49):47645-47652.

44. Kawashima K, et al. The estrogen-occupied estrogen receptor functions as a negative regulator to inhibit cell proliferation induced by insulin/IGF-1: a cell context-specific antimitogenic action of estradiol on rat lactotrophs in culture. Endocrinology. 2002;143(7):2750-2758

45. Cascio S, Bartella V, Garofalo C, Russo A, Giordano A, Surmacz E. Insulin-like growth factor 1 differentially regulates estrogen receptor-dependent transcription at estrogen response element and AP-1 sites in breast cancer cells. J Biol Chem. 2007; 282(6):3498-3506

46. Beretta L, Gingras AC, Svitkin YV, Hall MN, Sonenberg N. Rapamycin blocks the phosphorylation of 4E-BP1 and inhibits cap-dependent initiation of translation. EMBO J. 1996;15(3):658-664.

47. Wullschleger S, Loewith R, Hall MN. TOR signaling in growth and metabolism. Cell. 2006;124(3):471-484.

48. Sasaoka T, Rose DW, Jhun BH, Saltiel AR, Draznin $\mathrm{B}$, Olefsky JM. Evidence for a functional role of Shc proteins in mitogenic signaling induced by insulin, insulin-like growth factor-1, and epidermal growth factor. J Biol Chem. 1994;269(18):13689-13694.

49. Skolnik EY, et al. The $\mathrm{SH} 2 / \mathrm{SH} 3$ domain-containing protein GRB2 interacts with tyrosine-phosphorylated IRS1 and Shc: implications for insulin control of ras signalling. EMBO J. 1993;12(5):1929-1936.

50. Bol DK, Kiguchi K, Gimenez-Conti I, Rupp T, DiGiovanni J. Overexpression of insulin-like growth factor-1 induces hyperplasia, dermal abnormalities, and spontaneous tumor formation in transgenic mice. Oncogene. 1997;14(14):1725-1734

51. Russo IH, Russo J. Mammary gland neoplasia in long-term rodent studies. Environ Health Perspect. 1996;104(9):938-967.

52. Tian J, et al. Transgenic insulin-like growth factor-1 stimulates activation of COX-2 signaling in mammary glands [published online ahead of print October 17, 2011]. Mol Carcinog. doi:10.1002/mc.20868.

53. Donovan EA, Kummar S. Role of insulin-like growth factor-1R system in colorectal carcinogenesis. Crit Rev Oncol Hematol. 2008;66(2):91-98.

54. Sugumar A, Liu YC, Xia Q, Koh YS, Matsuo K Insulin-like growth factor (IGF)-I and IGF-binding protein 3 and the risk of premenopausal breast cancer: a meta-analysis of literature. Int J Cancer. 2004; 111(2):293-297.

55. Schernhammer ES, Holly JM, Hunter DJ, Pollak MN, Hankinson SE. Insulin-like growth factor-I, its binding proteins (IGFBP-1 and IGFBP-3), and growth hormone and breast cancer risk in The Nurses Health Study II. Endocr Relat Cancer. 2006; 13(2):583-592.

56. Lund MJ, et al. Race and triple negative threats to breast cancer survival: a population-based study in Atlanta, GA. Breast Cancer Res Treat. 2009, 113(2):357-370.

57. Carey LA, et al. Race, breast cancer subtypes, and survival in the Carolina Breast Cancer Study. JAMA. 2006;295(21):2492-2502.

58. Aloia JF, Mikhail M, Pagan CD, Arunachalam A, Yeh JK, Flaster E. Biochemical and hormonal variables in black and white women matched for age and weight. J Lab Clin Med. 1998;132(5):383-389.

59. D'Aloisio AA, et al. IGF-I and IGFBP-3 polymorphisms in relation to circulating levels among African American and Caucasian women. Cancer Epidemiol Biomarkers Prev. 2009;18(3):954-966.

60. Yanovski JA, Sovik KN, Nguyen TT, Sebring NG. Insulin-like growth factors and bone mineral density in African American and White girls. J Pediatr. 2000;137(6):826-832.
61. Wong WW, Copeland KC, Hergenroeder AC, Hill RB, Stuff JE, Ellis KJ. Serum concentrations of insulin, insulin-like growth factor-I and insulin-like growth factor binding proteins are different between white and African American girls. J Pediatr. 1999; 135(3):296-300.

62. Baglietto L, English DR, Hopper JL, Morris HA, Tilley WD, Giles GG. Circulating insulin-like growth factor-I and binding protein- 3 and the risk of breast cancer. Cancer Epidemiol Biomarkers Prev. 2007; 16(4):763-768.

63. Rinaldi S, et al. IGF-I, IGFBP-3 and breast cancer risk in women: The European Prospective Investigation into Cancer and Nutrition (EPIC). Endocr Relat Cancer. 2006;13(2):593-605.

64. Ahn J, et al. Adiposity, adult weight change, and postmenopausal breast cancer risk. Arch Intern Med. 2007;167(19):2091-2102.

65. Li CI, Malone KE, Daling JR. Interactions between body mass index and hormone therapy and postmenopausal breast cancer risk (United States). Cancer Causes Control. 2006;17(5):695-703.

66. Morimoto LM, et al. Obesity, body size, and risk of postmenopausal breast cancer: the Women's Health Initiative (United States). Cancer Causes Control. 2002;13(8):741-751

67. Abul-Hajj YJ. Relationship between estrogen receptors, 17 beta-hydroxysteroid dehydrogenase and estrogen content in human breast cancer. Steroids. 1979;34(2):217-225

68. Moseson M. Estrogen receptors and response to surgical adjuvant chemotherapy for breast cancer - hypothesized relationship to tumor stroma. Oncology. 1982;39(2):83-87.

69. Cheng D, Cote J, Shaaban S, Bedford MT. The arginine methyltransferase CARM1 regulates the coupling of transcription and mRNA processing. $\mathrm{Mol}$ Cell. 2007;25(1):71-83.

70. Shirley SH, et al. Transcriptional regulation of estrogen receptor-alpha by $\mathrm{p} 53$ in human breast cancer cells. Cancer Res. 2009;69(8):3405-3414. 